\title{
A Systematic Review of Factors Influencing Medication Adherence to Hypertension Treatment in Developing Countries
}

\author{
Lipi Dhar, Jaya Dantas, Mohammed Ali \\ International Health Programme, Faculty of Health Sciences, Curtin University, Bentley, Australia \\ Email: drlipidhar@hotmail.com
}

How to cite this paper: Dhar, L., Dantas, J. and Ali, M. (2017) A Systematic Review of Factors Influencing Medication Adherence to Hypertension Treatment in Developing Countries. Open Journal of Epidemiology, 7, 211-250.

https://doi.org/10.4236/ojepi.2017.73018

Received: May 18, 2017

Accepted: August 6, 2017

Published: August 9, 2017

Copyright (c) 2017 by authors and Scientific Research Publishing Inc. This work is licensed under the Creative Commons Attribution International License (CC BY 4.0).

http://creativecommons.org/licenses/by/4.0/

\begin{abstract}
Background: Coronary heart disease (CHD), a complication of hypertension, is one of the most important and common causes of morbidity, hospitalisation, and mortality among hypertensive population. In recent decades, increased urbanisation and changes to lifestyle, diet and physical activity in developing countries have led to a major increase in the population incidence of chronic diseases including CHD. Poor medication adherence is one of the leading causes of failure to achieve hypertension control. The objective of this systematic review is to describe the prevalence of non-adherence to antihypertensive medications among hypertensive population in developing countries and identify factors associated with it. Methods: A literature search was conducted using the following scholarly electronic databases: Proquest, PubMed, JSTOR and Science Direct. The online search engine, Google Scholar was also used to search for and identify relevant papers. Peer-reviewed fulltext articles published in English on hypertensive adults in developing countries that measured adherence to antihypertensive medications and their associations with different factors were eligible for inclusion. The review followed the PRISMA reporting and analytical guidelines for systematic reviews. Results: In all, 42 studies conducted across 19 developing countries were selected for the review. The mean prevalence of medication non-adherence (MNA) among the select hypertensive population was $47.34 \%$. Very few studies were conducted in community settings and except for one, no study examined gender differences in MNA factors. The analysis revealed a range of factors that can influence MNA including low household income and socioeconomic status; knowledge and beliefs of hypertension and its management; avoiding side effects of medications; cost of medication; use of herbal preparations; absence of symptoms; irregular follow-up; and dissatisfaction with the treatment and health services provided. There was a general lack of consideration of role of health system in health care delivery, self-efficacy, cultural barriers, per-
\end{abstract}


ceived individual risk of hypertension complications. There was also a lack of gender-specific research which is necessary at community settings given the social and economic vulnerabilities faced by women in developing countries that may affect adherence to antihypertensive medications. Conclusions: Future research in developing countries should consider individual risk perceptions, cultural barriers, gender and the role of local health system in health care delivery when assessing MNA among hypertensive population at community settings.

\section{Keywords}

Medication Adherence, Compliance, Hypertension, Antihypertensive Treatment, Developing Countries

\section{Introduction}

High blood pressure or hypertension is one of the most important risk factors for cardiovascular disease and a leading cause of premature adult deaths worldwide [1]. Uncontrolled hypertension causes $50 \%$ of the total coronary heart disease (CHD) deaths globally [1]. An analysis of global data reveals that of the deaths from CHD approximately $80 \%$ will occur in low and middle-income countries, [2] and this is particularly common among people of low socioeconomic status [3] [4]. Regardless of race or ethnicity, the disease also accounts for the death of one in three women globally [5] with an estimated 3.4 million women dying from CHD every year worldwide [6].

Among all the WHO regions, the prevalence of hypertension is highest in the African Region (46\%) and lowest in the region of the Americas (35\%) [7]. One in three adults in the South East Asia region has hypertension [7]. Findings from recent studies also indicate a higher prevalence of hypertension in middle-aged and older women compared to men in developing countries [8] [9] [10] and CHD causes significant morbidity and mortality in women during childbearing years [11].

In developed countries, strong public health policies, multi-sectored preventive action and widely available diagnosis and treatment have led to an appreciable reduction in the prevalence of high blood pressure (BP) [7]. As little as 2 $\mathrm{mmHg}$ population-wide decrease in BP can prevent 151,000 strokes and 153,000 CHD deaths globally [12]. Despite the availability of over a hundred different effective drugs for hypertension treatment, the reported rates of blood pressure control are very disappointing [13]. Between 2000 and 2013, the number of deaths attributable to hypertension rose from 7.6 to 9.4 million [14]. A systematic review of the studies published from 2001 to 2007 revealed that BP was poorly controlled in developing countries, the mean proportion of control of hypertension among all hypertensive patients being only 13\% [15]. Poor medication adherence is one of the leading causes of failure to achieve BP control 
[16]. In developing countries, the degree of non-adherence is assumed to be higher particularly due to the shortage of health resources and difficulties in access to healthcare [4].

The WHO defines adherence to long term therapy as "the extent to which a person's behaviour-taking medication, following a diet, and, or executing lifestyle changes corresponds with agreed recommendations from a healthcare provider" [4]. The term compliance to medicine is defined as "the extent to which a patient acts in accordance with the prescribed interval and dose of the dosing regimen" reported as a percentage of prescribed doses taken at the prescribed time interval [17] [18]. Despite these variations, these terminologies have been used interchangeably in most studies [19]. Most of the studies on adherence have been undertaken in developed countries. However, healthcare access, cultural beliefs, education about chronic illnesses and the functions of medication, the nature of patient-physician interactions and social support, among many other factors, are very different in developing countries compared to developed countries and may profoundly affect rates of medication adherence [20] [21].

Over the past decade, though some studies have been conducted in developing countries to explore the factors influencing medication adherence among hypertensive patients, little has been documented about MNA and its determinants of hypertensive patients. This systematic review was conducted to address this gap and examine the prevalence of MNA among hypertensive patients as well as investigate factors affecting MNA in this population.

\section{Methods}

Literature search was conducted using the electronic databases: Proquest, PubMed, JSTOR and Science Direct for articles published during 2000-15. The online search engine, Google Scholar was also used to search for and identify likely papers. The search strategy included the following terms:

- adherence, non-adherence, compliance, persistence (related to medication adherence).

- hypertension, high blood pressure (Blood pressure $\geq 140 / \geq 90 \mathrm{~mm}$ of $\mathrm{Hg}$ ).

- belief, perception of hypertension and

- developing countries (the World Bank classifies all low- and middle-income countries as developing countries-however, this term is not intended to imply that all economies in the group are experiencing similar development or that other economies have reached a preferred or final stage of development).

\subsection{Study Selection}

From the initial search, 1425 titles and abstracts were identified. Duplicates were removed. Abstracts and titles were screened for relevance, and an initial list of 124 relevant articles was made (Figure 1). The full-texts of these articles were then examined to determine eligibility for inclusion in the systematic review using the following selection criteria:

The inclusion criteria for the review were clinical research: 


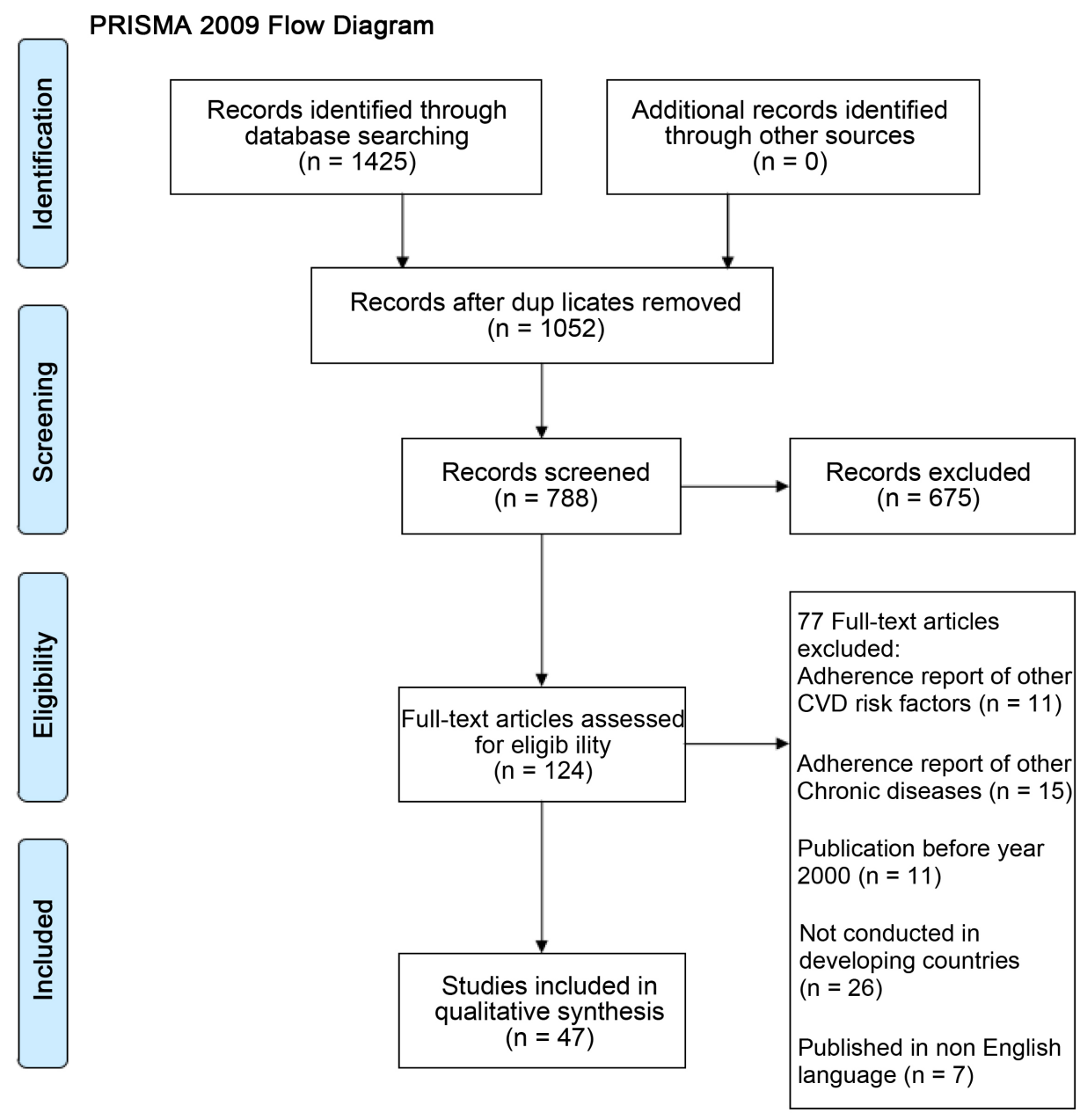

From: Moher D, Liberati A, Tetzlaff J, Altman DG, The PRISMA Group (2009). Preferred Reporting Items for Systematic Reviews and Meta-Analyses: The PRISMA Statement. PLoS Med 6(6): e1000097. doi: 10.1371/journal.pmed1000097 For more information, visit www. prisma-statement.org.

Figure 1. Results of screening process.

1) Measured adherence to antihypertensive medications in developing countries.

2) Identify factors related to medication adherence with the antihypertensive treatment.

3) Enrolled hypertensive adults (18 years and older).

4) Published in English as a peer-reviewed full-text article.

We excluded studies that measured adherence of other chronic diseases or were conducted in developed countries and published in a non-English language.

\subsection{Data Extraction and Analysis}

The total number of relevant articles meeting the above criteria was 47 , consisting of 45 peer-reviewed journal articles and two thesis papers: 40 were on quantitative studies, five on qualitative studies and two were mixed methods stu- 
dies.To check the quality of quantitative studies the National Collaborating Centre for Methods and Tools' quality assessment tool for quantitative studies was used [22]. Qualitative studies were checked based on NICE guidelines [23].

A standardised data extraction form was used to record the citation details, methodology and objectives, and main findings of each paper. The following information was extracted and tabulated by the first reviewer and verified by the second and third reviewers: author name, date of publication, the country in which research was conducted, sample size, sampling method, study design, sex (\% female), the adherence measure used, key findings and any statistical information (odd ratios, 95\% CI p-value, correlation coefficients). A summary of the studies reviewed was provided in Table 1. A meta-analysis of the findings was not possible due to the heterogeneity in important aspects of methodology of the

Table 1. Summary of variables under the domain of demographic factors investigated by the studies.

\begin{tabular}{|c|c|c|c|}
\hline $\begin{array}{l}\text { Variables being } \\
\text { investigated }\end{array}$ & Study & $\begin{array}{c}\text { Measurement of } \\
\text { medication } \\
\text { adherence }\end{array}$ & Setting and sample size \\
\hline \multirow{5}{*}{ Age } & Boima et al. [26] & MMAS 8 & $\begin{array}{l}\text { Ghana and Nigeria; } \\
\qquad \mathrm{N}=357\end{array}$ \\
\hline & Nagarkar et al. [27] & MMAS 8 & India; $N=174$ \\
\hline & Bilal et al. [60] & Questionnaire & Pakistan; $\mathrm{N}=113$ \\
\hline & Lalic et al. [28] & MMAS 8 & Serbia; $N=170$ \\
\hline & Khanam et al. [29] & Questionnaire & Bangladesh; $\mathrm{N}=29,960$ \\
\hline \multirow{4}{*}{ Sex } & Praveen et al. [30] & Questionnaire & India; $N=804$ \\
\hline & Ismael et al. [31] & Questionnaire & Iraq; $N=200$ \\
\hline & Bilal et al. [60] & Questionnaire & Pakistan; $\mathrm{N}=113$ \\
\hline & Joho et al. [32] & Questionnaire & Tanzania; $\mathrm{N}=135$ \\
\hline \multirow{3}{*}{$\begin{array}{c}\text { Level of } \\
\text { education }\end{array}$} & Khanam et al. [29] & Questionnaire & Bangladesh; $\mathrm{N}=29,960$ \\
\hline & Bhandari et al. [33] & MMAS 4 & Nepal; $N=154$ \\
\hline & Boima et al.[26] & MMAS 8 & $\begin{array}{l}\text { Ghana and Nigeria; } \\
\qquad \mathrm{N}=357\end{array}$ \\
\hline \multirow{3}{*}{$\begin{array}{l}\text { Household } \\
\text { income and } \\
\text { employment }\end{array}$} & Hussain et al. [34] & Questionnaire & Bangladesh; $N=120$ \\
\hline & Gelaw et al. [35] & Questionnaire & Ethiopia; $\mathrm{N}=91$ \\
\hline & Bilal et al. [40] & Questionnaire & Pakistan; $N=113$ \\
\hline \multirow[t]{3}{*}{ Type of family } & Nagarkar et al. [27] & MMAS 8 & India; $N=174$ \\
\hline & Hareri et al. [36]. & Questionnaire & Ethiopia; $\mathrm{N}=365$ \\
\hline & Khanam et al. [29] & Questionnaire & Bangladesh; $\mathrm{N}=29,960$ \\
\hline \multirow[t]{2}{*}{ Comorbidities } & Ambaw et al. [37] & MMAS 4 & Ethiopia; $\mathrm{N}=384$ \\
\hline & $\begin{array}{c}\text { Al-Ramahi et al. } \\
\text { [38]. }\end{array}$ & MMAS 8 & Palestine $; \mathrm{N}=450$ \\
\hline \multirow{3}{*}{$\begin{array}{l}\text { Use of herbal } \\
\text { preparation }\end{array}$} & Boima et al. [26]. & MMAS 8 & $\begin{array}{l}\text { Ghana and Nigeria; } \\
\qquad \mathrm{N}=357\end{array}$ \\
\hline & Saleem et al. [39] & Qualitative & Pakistan \\
\hline & Odusola et al. [40] & Qualitative & Nigeria \\
\hline
\end{tabular}


selected studies including sampling procedure (random/purposive) population ages, study settings (hospital/clinic/community), study design (cross-sectional/ longitudinal/qualitative) and measurement procedure of medication adherence. Descriptive analysis of studies examining similar variables and any association observed were considered to offer a simple indication of the level of evidence. Summary ranges of quantitative proportions and measures relating to prevalence and factors associated with MNA were compiled and presented. The evidence from the studies was synthesised and presented in a narrative review. The review followed the PRISMA reporting guidelines [24].

\section{Result}

\subsection{Description of the Studies}

The selected studies were conducted in developing countries in Asia (22) Africa (17), the Middle East (4), South America (2), and Europe (1). Among the 42 quantitative studies, the majority (33 studies [78.57\%]) were conducted in urban hospital or clinic settings, with only nine studies were carried out in community settings (five in India and one each from Bangladesh, Nepal and Nigeria). Most of the studies (34 studies) were cross-sectional quantitative in type. A study from Nigeria was mixed methods in type, comprising both quantitative and qualitative methods for data collection [25]. A summary of the characteristics and the aim of each study are shown in Table A1.

The five qualitative studies were from India (1), Pakistan (1), Congo (1), Malaysia (1) and Nigeria (1). Three studies used one-to-one qualitative interviews, one study used focus group discussion, and one used a combination of these methods. Further details of the study designs and results are presented in Table A1. In all of the studies, the study population included both males and females. Overall women comprised $55.98 \%$ of study participants.

\subsection{Reported Adherence to Antihypertensive Treatment}

To measure medication adherence, 21 (50\%) of the quantitative studies used the Morisky Medication Adherence Scale'. Other scales used in the four different studies were: Medicines Team Questionnaire-Qualiaids (QAM-Q) (1); Beliefs about Medicine Questionnaire (BMQ) (1); Hill-Bone Adherence to Blood Pressure Therapy Scale (1); Drug Attitude Inventory (DAI-10) (1); One study used Medication Event Monitoring System (MEMS) and one used pill count to measure adherence. The remaining studies used questionnaires. Among them, eleven studies used structured questionnaires with established reliability and or validity, while eight studies (33\%) did not cite information on their reliability or validity. The rate of MNA among hypertensive population ranged from $23 \%-6.76 \%$ with the mean being $47.34 \%$.

\subsection{Factors Impacting on Adherence}

The identified factors related to MNA in the reviewed studies could be catego- 
rised into seven domains: demographic; psychosocial; perceptions regarding hypertension and its severity; perceptions regarding antihypertensive treatment; perceived barriers to treatment adherence; treatment and disease related factors; and health care services.

\subsubsection{Demographic Factors}

Sixteen studies reported significant associations between demographic variables (such as age, sex, level of education, types of family, household income, employment, type of family, co-morbidities and use of herbal preparations)and MNA to hypertensive therapy (Table 1 ).

The effect of age on medication adherence showed conflicting results. Younger age was found to be significantly associated with MNA to hypertensive medications in India ( $\leq 57$ years) [OR (odd ratio) 3.348; 95\% Confidence Interval (CI): 1.665 - 6.732] [27], Palestine ( $<45$ years) $(\mathrm{OR}=0.40$; 95\% CI: $0.157-0.99)$ [38] and Pakistan ( $\leq 51$ years) (OR $=1.0 ; 95 \%$ CI: $1.00-1.04)$. The mean age of hypertensive patients who were not adherent to medications was $54.5 \pm 13.2$ years while those who were adherent had a mean age of $60.9 \pm 12.1$ years $(P<$ $0.001)$ in Ghana and Nigeria [26]. On the other hand, a significantly lower level of adherence was identified in a study with elderly patients in Serbia. In this study patients less than 65 years were found to be more likely to adhere to their prescribed treatment, compared to older patients $(\mathrm{AOR}=6.0 ; 95 \% \mathrm{CI}: 2.76$ 13.04) [28].

Being female was independently and significantly associated with poor adherence in a study in India ( $\mathrm{AOR}=2.95 ; 95 \%$ CI: 1.39 - 6.24) with hypertensive women 2.95 times more likely to be non-adherent to their medications than men [30]. A study in Iraq also revealed that female hypertensive patients (61.7\%) were more non-adherent than male (30.3\%) patients [31]. On the other hand, MNA was significantly associated with male gender in Pakistan $(P=0.008)$ [60], Tanzania $(P=0.044)$, [32] and Bangladesh $(\mathrm{AOR}=1.67 ; 95 \% \mathrm{CI}: 1.42-1.97)$ [29]. However, several studies [26] [33] [34] [41] [42] found no significant association between gender and MNA among hypertensive patients. Thus, the effect of gender on MNA showed conflicting results across countries.

Hypertensive patients in Nepal who were illiterate almost five times less likely to be adherent to medications than those who were literate $(\mathrm{AOR}=5.34,95 \%$ CI: 1.23 - 23) [33]. Similarly, lower level of education was significantly associated with MNA among hypertensive patients in Bangladesh (OR $=6.34$; 95\% CI: 1.65 24.41) [34]. On the other hand, formal education was associated with MNA ( $P=$ $0.001)$ in Ghana and Nigeria [26]. A study in India found that educational level was not a significant contributing factor to non-adherence [43]. From these results, it seems that educational level may not always be a good predictor of MNA.

Hypertensive patients with low monthly income (AOR $=11.60 ; 95 \%$ CI: 3.77 35.65) in Bangladesh [34] and Ethiopia $(P=0.04)$ [35] were more non-adherent 
to their medications. In Pakistan, [44] the likelihood of MNA was also found to be higher among unemployed persons $(P=0.002)$ and people with low socioeconomic status $(P=0.046)$. Hypertensive patients who had private businesses were $72 \%$ less likely to adhere to medication compared to government employees $(\mathrm{AOR}=0.28,95 \% \mathrm{CI}: 0.130-0.606)$ in Ethiopia [45]. Hypertensive patients living in a nuclear family setup in India were more likely to have lower adherence to medication as compared to staying in the extended family $(\mathrm{OR}=2.67$; 95\% CI: 1.378 - 5.175) [27].

Hypertensive patients with co-morbidities were $50 \%$ less likely to be adherent to their medications compared to patients with no co-morbidity ( $\mathrm{AOR}=0.50$ : 95\% CI: 0.290 - 0.893) in Ethiopia [36]. In Bangladesh, hypertensive patients with cardiovascular co-morbidity were significantly associated with MNA (AOR = 0.79; 95\% CI: 0.64 - 0.97) [29]. A study in north-west Ethiopia [37] also found that patients with no and one co-morbidity were more likely to adhere to their treatment than those with two $(\mathrm{AOR}=2.50,95 \% \mathrm{CI}: 1.01-6.21)$ or more than two co-morbidities (AOR $=2.68,95 \% \mathrm{CI}: 1.07$ - 6.71). However, having no other chronic disease $(P=0.009)$ was a significant factor influencing MNA among hypertensive patients in Palestine [38].

In Ghana and Nigeria, patients who used herbal preparations for the treatment of hypertension were more likely to show MNA $(P=0.014)$ [26]. In a qualitative study in Pakistan, [39] almost all the hypertensive patients surveyed firmly supported the utilisation of traditional or herbal remedies for the control of their high BP and confirmed that usually only in the case of failure of these therapies would they seek help from modern or biomedical health care providers. A qualitative study in Nigeria found some patients with low medication adherence substituted or complemented prescribed pills with herbal remedies on their own without informing their doctor [40].

\subsubsection{Psychosocial Factors}

Seven studies reported significant associations between psychosocial variables (such as family support, depression and use of social drugs) and MNA to hypertensive treatment (Table 2).

An absence of household support had a strong negative effect on adherence among hypertensive patients in Ethiopia (AOR $=0.170,95 \% \mathrm{CI}: 0.030-0.905$ ) [46] and Nigeria ( $p<0.05)$ [47]. Likewise, studies [41] [49] in Congo reported that patients who received no support from family members regarding reminders about taking their medications were likely to be more non-compliant than the others. A qualitative study in Congo [49] found that there was a perception among some family members that the hypertensive patient had brought the condition upon him-/herself by being a bad person: "They say I developed hypertension because I killed her sister' (through witchcraft)." Though family cohesion is very high in Bangladesh, lack of an accompanying person to go to the physician/hospital was a significant factor in determining non-adherence to antihypertensive treatment $(\mathrm{OR}=3.54 ; 95 \% \mathrm{CI}: 1.04-11.99)$ [34]. This lack of 
Table 2. Summary of variables under the domain of psychosocial factors investigated by the studies.

\begin{tabular}{|c|c|c|c|}
\hline $\begin{array}{c}\text { Variables being } \\
\text { investigated }\end{array}$ & Study & Study design & $\begin{array}{l}\text { Study setting and } \\
\text { sample size }\end{array}$ \\
\hline & Hussain et al. [34] & Questionnaire & Bangladesh; $\mathrm{N}=120$ \\
\hline & Nsitou et al. & Questionnaire & Congo $; \mathrm{N}=212$ \\
\hline \multirow[t]{3}{*}{ Family support } & Lubaki et al. [48] & Qualitative & Congo \\
\hline & Ali et al. [46] & MMAS 8 & Ethiopia; $\mathrm{N}=121$ \\
\hline & Olowookere [47] & Questionnaire & Nigeria; $N=420$ \\
\hline Depression & Boima et al. [26] & MMAS 8 & Ghana and Nigeria; $\mathrm{N}=357$ \\
\hline \multirow[t]{4}{*}{ Use of social drugs } & Khanam [29] & Questionnaire & Bangladesh; $\mathrm{N}=29,960$ \\
\hline & Ahmed et al. [48] & MMAS 8 & India; $N=334$ \\
\hline & Kamran et al. [50] & MMAS 4 & Iran; $N=671$ \\
\hline & Bhandari et al. [33]. & MMAS 4 & Nepal; $\mathrm{N}=154$ \\
\hline
\end{tabular}

support may be due to lack of knowledge of the family members about the disease process. When patients are depressed, they are less likely to follow health care providers' treatment plan for hypertension. In Ghana and Nigeria [26] MNA occurred in patients who had varying degrees of depression $(r=-0.208, P<$ 0.001) ( $r=$ Pearson's correlation coefficient).

A World Health Organization report observed that alcohol abuse and tobacco smoking were important modifiers of compliance behaviour. Patients' habit of alcohol consumption, [29] [48] tobacco chewing, [48] and smoking [29] [48] [50] were strongly associated with poor adherence to anti-hypertensive treatment in studies in India, Iran and Ethiopia. In contrast, a study in Nepal did not found any significant association between tobacco use and alcoholism with MNA among hypertensive study participants [33].

\subsubsection{Perceptions Regarding Hypertension and Its Severity}

Four studies reported significant associations between variables related to perceptions of hypertension and MNA to hypertensive medications. These factors included: awareness, knowledge and belief of hypertension and knowledge of the severity of hypertension.

Researchers found that poor understanding and belief in high blood pressure were significant factors associated with MNA in Bangladesh (AOR $=12.90 ; 95 \%$ CI: 1.65 - 100.63) [34] and in Ethiopia $(P<0.01)$ [35]. A qualitative study in Pakistan [39] revealed that once patients achieved control of their high BP, they tended to discontinue their medications. Those patients with an inadequate knowledge of hypertension related complication were also more likely to be non-adherent with the treatment regimen, as found in a study in Bangladesh $(\mathrm{OR}=23.71 ; 95 \% \mathrm{CI}: 3.38$ - 166.46) [34] and Congo (OR = 2.9; 95\% CI: 1.61 5.29) [41]. Diagnosed hypertensive patients who lacked knowledge regarding the severity of hypertension were also more likely to be non-adherent to medica- 
tions in Congo $(\mathrm{AOR}=0.34: 95 \% \mathrm{CI}: 0.13$ - 0.94) [41] and Bangladesh $(\mathrm{AOR}=$ 23.71; 95\% CI: 3.38 - 166.46) [34].

\subsubsection{Perceptions Regarding Antihypertensive Treatment}

Eight studies found significant associations between variables related to antihypertensive treatment and MNA (Table 3).

Studies in Congo (AOR = 0.36; 95\% CI: (0.15 - 0.83), [41] Bangladesh (AOR = 24.50; 95\% CI: 6.28 - 95.58), [34] and Ethiopia [35] $(P<0.01)$ reported that patients' lack of knowledge about hypertension management was significantly associated with non-adherence to therapy. A significant correlation between beliefs about medication and MNA was found among hypertensive patients in Ghana and Nigeria [26] with patients who were worried about the adverse effects of antihypertensive drugs less likely to be adherent to their medications ( $r=$ -0.0347, $P=0.002)$. Qualitative studies in Pakistan [39] and Malaysia [51] also found patients hesitated to take medications continuously due to their lack of belief in medications. As one hypertensive patient in Pakistan commented: " $M e$ dications are hot (warm) in nature. They enter the stomach and increase temperature which interferes with digestion." A study in Palestine found that patients with hypertension were not adhering to their medication due to the fear of dependent on medicines (AOR $=8.00 ; 95 \%$ CI: $(2.44-26.19)$ [38]. Similarly avoiding side effects of drugs (AOR $=3.0$; 95\% CI: 1.4 - 6.7) was an important reason for non-adherence to their treatment regimen among hypertensive patients in Nigeria [42].

Hypertensive patients who did not understand their drug regimen well were poorly adherent to their prescribed medications $(\mathrm{AOR}=4.06,95 \% \mathrm{CI}: 1.01$ 16.32) in India [30] and Ethiopia (AOR $=0.12,95 \% \mathrm{CI}=0.258-0.583)$ [36].

Table 3. Variables summarised under the domain of perceived barriers to antihypertensive treatment and MNA investigated by studies.

\begin{tabular}{|c|c|c|c|}
\hline $\begin{array}{l}\text { Variables being } \\
\text { investigated }\end{array}$ & Study & $\begin{array}{c}\text { Measurement of } \\
\text { medication } \\
\text { adherence }\end{array}$ & $\begin{array}{l}\text { Study setting and } \\
\text { sample size }\end{array}$ \\
\hline \multirow{3}{*}{$\begin{array}{l}\text { Knowledge about } \\
\text { hypertension } \\
\text { management }\end{array}$} & Hussain et al. [34] & Questionnaire & Bangladesh; $\mathrm{N}=120$ \\
\hline & Nsitou et al. [41] & Questionnaire & Congo; $\mathrm{N}=212$ \\
\hline & Gelaw et al. [35] & Questionnaire & Ethiopia; $\mathrm{N}=91$ \\
\hline \multirow{4}{*}{$\begin{array}{l}\text { Belief about } \\
\text { medication }\end{array}$} & Boima et al. [26] & MMAS 8 & $\begin{array}{l}\text { Ghana and Nigeria; } \\
\qquad \mathrm{N}=357\end{array}$ \\
\hline & Saleem et al. [39] & Qualitative & Pakistan \\
\hline & Shima et al. [51] & Qualitative & Malaysia \\
\hline & Al-Ramahi et al. [38] & MMAS 8 & Palestine; $\mathrm{N}=450$ \\
\hline \multirow{3}{*}{$\begin{array}{l}\text { Avoiding side effect } \\
\text { of medications }\end{array}$} & Campbell et al. [42] & MMAS 4 & Nigeria; $N=262$ \\
\hline & Hareri et al. [36] & Questionnaire & Ethiopia; $N=365$ \\
\hline & Praveen et al. [30] & Questionnaire & India; $N=804$ \\
\hline \multirow{2}{*}{$\begin{array}{l}\text { Do not understand } \\
\text { drug regimen well }\end{array}$} & Gelaw et al. [35] & Qualitative & Ethiopia \\
\hline & Odusola et al. [40] & Qualitative & Nigeria \\
\hline
\end{tabular}


Gelaw et al. [35] found that insufficient information about the consequence of non-adherence to hypertension treatment contributed to the non-adherence of the hypertensive patients in Ethiopia. In Nigeria, a qualitative study also found ignorance about regular use of medication was an important contributor to medication non-adherence [40].

\subsubsection{Perceived Barriers to Adherence}

Sixteen studies found significant associations between aspects related to perceived barriers and MNA. These perceived barriers were: the cost of medications, the number of pills that needed to be taken on a daily basis, forgetfulness, side effects of medications, duration of therapy, satisfaction with the treatment and health services provided, and distance from health care centre (Table 4).

Table 4. Variables investigated under the domain of perceived barriers and MNA.

\begin{tabular}{|c|c|c|c|}
\hline $\begin{array}{l}\text { Variables being } \\
\text { investigated }\end{array}$ & Study & $\begin{array}{c}\text { Measurement of } \\
\text { adherence }\end{array}$ & $\begin{array}{l}\text { Study setting and } \\
\text { sample size }\end{array}$ \\
\hline \multirow{4}{*}{ Cost of medications } & Bhandari et al. [33] & MMAS 4 & Nepal; $\mathrm{N}=154$ \\
\hline & Nsitou [41]. & Questionnaire & Congo $; \mathrm{N}=212$ \\
\hline & Eizubier [52] & Pill count & Sudan $; N=198$ \\
\hline & Praveen [30] & Questionnaire & India; $N=804$ \\
\hline \multirow{6}{*}{ Number of pills } & Bhandari et al. [33] & MMAS 4 & Nepal; $\mathrm{N}=154$ \\
\hline & Srikanth et al. [53] & MMAS 8 & India; $\mathrm{N}=304$ \\
\hline & Olowookere [47] & Questionnaire & Nigeria; $N=420$ \\
\hline & Ramli [54] & $\begin{array}{c}\text { The hill bone } \\
\text { adherence to BP scale } \\
\text { and MMAS } 8\end{array}$ & Malaysia; $\mathrm{N}=653$ \\
\hline & Bilal et al. [44] & Questionnaire & Pakistan; $\mathrm{N}=113$ \\
\hline & Srivastava et al. [55] & $\begin{array}{l}\text { Self-report and } \\
\text { MMAS } 4\end{array}$ & India; $\mathrm{N}=440$ \\
\hline \multirow{2}{*}{ Forgetfulness } & Campbell et al. [42] & Morisky Green & Nigeria; $\mathrm{N}=262$ \\
\hline & Al-Ramahi [38] & MMAS 8 & Palestine; $\mathrm{N}=450$ \\
\hline \multirow{3}{*}{$\begin{array}{l}\text { Side effect of medi- } \\
\text { cine }\end{array}$} & Lalic et al. [28] & MMAS 8 & Serbia ; $N=170$ \\
\hline & Shima $[51]$ & Qualitative & Malaysia \\
\hline & Odusola [40] & Qualitative & Nigeria \\
\hline \multirow{5}{*}{ Duration of therapy } & Bhandari et al. [33] & MMAS 4 & Nepal; $\mathrm{N}=154$ \\
\hline & Hareri et al. [45] & Questionnaire & Ethiopia; $\mathrm{N}=286$ \\
\hline & Lalic et al. [28] & MMAS 8 & Serbia; $N=170$ \\
\hline & Bilal et al. [44] & Questionnaire & Pakistan; $\mathrm{N}=113$ \\
\hline & Hu et al. [56] & Questionnaire & China; $\mathrm{N}=318$ \\
\hline \multirow{3}{*}{$\begin{array}{c}\text { Distance from } \\
\text { health care facilities }\end{array}$} & Gelaw et al. [35] & Questionnaire & Ethiopia; $\mathrm{N}=91$ \\
\hline & Al Ramahi [38] & MMAS 8 & Palestine; $\mathrm{N}=450$ \\
\hline & Ambaw et al. [37]. & MMAS 4 & Ethiopia; $\mathrm{N}=384$ \\
\hline
\end{tabular}


In non-adherent patients surveyed in Nepal, a significantly greater proportion of patients considered the price of medications to be too high (AOR $=5.14 ; 95 \%$ CI: $1.1-23.9)$ [33] and for which they missed taking their medications (AOR = 0.143 ; 95\% CI: 0.02 - 0.78). The cost of medicine was also a significant factor associated with MNA among patients in Congo (OR $=1.84$; 95\% CI: 0.93 - 3.64) [41]. Similarly, the inability to buy medications $(P<0.001)$ was positively and significantly related to MNA in Sudan [52]. Even being able to afford only some of the prescribed antihypertensive drugs $(\mathrm{AOR}=3.70,95 \% \mathrm{CI}: 1.81-7.59)$ was also significantly related with MNA in India [30].

In Nepal, non-adherence was significantly associated with therapy requiring more than one pill per day (AOR $=5.33$; 95\% CI: 1.19 - 23.7) compared to patients prescribed only one pill per day [33]. MNA was also greater among patients with higher pill burden in India, [53] Nigeria, [47] and Malaysia [54] $(P<$ 0.05). On the other hand, a couple of studies [44] [55] found that when patients had to take multiple medications, perhaps, they were less likely to fail to remember to take them, compared to having only one pill. A study in Pakistan [44] found non-adherence was higher among those patients who were on monotherapy and di-therapy compared to patients using 3 or $>3$ drugs $(P=0.02)$.

Patients also often forget to take even once daily medications. Studies in Nigeria $(\mathrm{OR}=14.8$; 95\% CI: $3.9-54.8)$ [42] and Palestine (AOR = 5.12; 95\% CI: $3.12-8.41)$ [38] found significant correlation between forgetfulness and nonadherence among hypertensive patients.

Hypertensive patients who experienced side effects of their medications were less adherent to their medication than those who did not experience side effects in Palestine ( $\mathrm{AOR}=4.58 ; 95 \% \mathrm{CI}: 1.87-11.25)$ and Serbia $(\mathrm{OR}=7.95 ; 95 \% \mathrm{CI}$ : 1.48 - 42.6) [28] [38]. Qualitative studies in Malaysia [51] and Nigeria [40] also found perceived side effects were inhibitors of antihypertensive medication adherence. However, Praveen et al. [30] in India did not find a correlation between adverse drug events and non-adherence.

Patients who had had a diagnosis of hypertension of five or more years were less likely to adhere to treatment than those who had been diagnosed for less than five years in Nepal [33] (OR $=2.98 ; 95 \%$ CI: $1.73-5.14)$ and Ethiopia $(\mathrm{AOR}=$ 0.11, 95\% CI: 0.013 - 0.955) [45]. Lower levels of adherence in elderly patients with longer duration of antihypertensive therapy were also found in Serbia [28]. On the other hand, patients with shorter duration of hypertension were less likely to be adherent to treatment in Pakistan ( $<5$ years) (AOR $=0.11,95 \% \mathrm{CI}$ : $0.013-0.955)[44]$ and China ( $<3$ years $)(\mathrm{AOR}=3.31$; $95 \% \mathrm{CI}: 1.91-5.72 ; \mathrm{P}<$ $0.001)[56]$.

Distance from health care facilities was a significant barrier for adherence to treatment. Longer distance from medical centres contributed to MNA of hypertensive patients in Ethiopia [35]. In the same way, those living in rural areas had poorer adherence to hypertensive medications in Palestine than those living in urban areas ( $\mathrm{AOR}=1.79 ; 95 \% \mathrm{CI}: 1.10$ - 2.92) [38]. As the remoteness from the hospital decreased, adherence to hypertension treatment improved $(\mathrm{AOR}=2.02$; 
95\% CI: 1.19 - 3.43) in Ethiopia [37].

\subsubsection{Treatment and/or Disease Related Factors}

Eleven studies found a number of treatment or disease related factors associated with MNA. These included absence of disease symptoms, complication, irregular follow-up, family history of hypertension and poor BP control (Table 5).

The absence of symptoms significantly contributed to poor compliance to hypertensive therapy in Nigeria $(\mathrm{AOR}=3.3$; 95\% CI: $(1.3-8.0)$ [42] and India $(\mathrm{OR}=$ 0.414; 95\% CI: 0.192 - 0.892) [27]. Qualitative studies in Congo [49] and India [58] also found hypertensive medications were more likely to be taken when the patient experienced symptoms of hypertension.

The presence of hypertension-related complications such as heart diseases $(\mathrm{AOR}=21.73,95 \% \mathrm{CI}: 1.568-418.42 P=0.000)$ was found to be associated with decreased medication adherence among patients in Ethiopia [46]. In contrast, a study in Pakistan found that cases suffering from hypertension-related complications were more likely to be adherent to medications [57].

In Nepal, those with no family history of hypertension were less adherent to their medications compared to those with a family history of high BP (OR =

Table 5. Variables summarised under the domain of treatment and/or disease related factors investigated by the studies.

\begin{tabular}{|c|c|c|c|}
\hline $\begin{array}{l}\text { Variables being } \\
\text { investigated }\end{array}$ & Study & $\begin{array}{l}\text { Measurement of } \\
\text { medication adherence }\end{array}$ & $\begin{array}{l}\text { Study setting and } \\
\text { sample size }\end{array}$ \\
\hline \multirow{5}{*}{$\begin{array}{l}\text { Absence of disease } \\
\text { symptoms }\end{array}$} & Campbell et al. [42] & Morisky Green & Nigeria $; N=262$ \\
\hline & Nagarkar et al. [27] & MMAS 8 & India; $N=174$ \\
\hline & Lubaki et al. [49] & Qualitative & Congo \\
\hline & Kusuma et al. & Qualitative & India \\
\hline & Odusola [40] & Qualitative & Nigeria \\
\hline \multirow{2}{*}{$\begin{array}{c}\text { Presence of } \\
\text { hypertension related } \\
\text { complications }\end{array}$} & Ali et al. [46] & $\begin{array}{l}\text { MMAS } 8 \text { and patient } \\
\text { medication chart }\end{array}$ & Ethiopia; $N=121$ \\
\hline & Hashmi et al. [57] & $\begin{array}{l}\text { History of pill taken } \\
\text { and MMAS } 4\end{array}$ & Pakistan \\
\hline $\begin{array}{l}\text { Family history of } \\
\text { hypertension }\end{array}$ & Bhandari et al. [33] & MMAS 4 & Nepal; N = 154 \\
\hline \multirow{2}{*}{ Irregular follow up } & Bhandari et al. [33] & MMAS 4 & Nepal; N = 154 \\
\hline & Praveen et al. [30]. & Questionnaire & India; $\mathrm{N}=804$ \\
\hline \multirow{4}{*}{$\begin{array}{l}\text { Blood pressure } \\
\text { control }\end{array}$} & Boima et al. [26] & MMAS 8 & $\begin{array}{l}\text { Ghana and Nigeria } \\
\qquad \mathrm{N}=357\end{array}$ \\
\hline & Lalic et al. [28] & MMAS 8 & Serbia; $N=170$ \\
\hline & Ramli [54] & $\begin{array}{l}\text { The hill bone } \\
\text { adherence to BP } \\
\text { and MAASA } 8\end{array}$ & Malaysia; $\mathrm{N}=653$ \\
\hline & Ali et al. [46] & MMAS 8 & Ethiopia; $N=121$ \\
\hline
\end{tabular}


4.46; 95\% CI: 1.21 - 16.4, $\mathrm{P}=0.024$ ) [33]. Frequent meetings/appointments provide better monitoring of blood pressure levels, as well as the opportunity to have more access to information and can serve as the basis for adherence to antihypertensive medication management [59]. Irregular follow-up (AOR = 6.39; 95\% CI: 1.22 - 33.3), [33] was significantly associated with MNA in Nepal. Similarly, an Indian study reported that a longer time since the last visit to a doctor for advice $(\mathrm{AOR}=7.26,95 \% \mathrm{CI}: 2.65$ - 19.86) was significantly related with nonadherence to hypertensive medications [30].

Poor BP control was significantly associated with MNA in Ghana and Nigeria $(P=0.006)$ [26]. BP values over $140 / 90 \mathrm{mmHg}$ were also reported in $59.1 \%$ of non-adherent patients and $21.4 \%$ of adherent patients, [Chi Square $\left(\chi^{2}\right)=19.84$; $P<0.01 ;$ OR $=5.3095 \%, C I: 2.39-11.85$ ] in Serbia [28]. Similarly, the average systolic and diastolic blood pressure for non-adherents was significantly higher $(P=0.05)$ than that in adherents in Malaysia [54]. In contrast, a study in Northern Ethiopia [46] found that patients at the pre-hypertension level (BP values below 140/90 mmHg) (AOR = 0.026; 95\% CI: $0.003-0.242)$ were less adherent to their medications.

\subsubsection{Health Care Services}

Four studies found dissatisfaction with the health services and treatment provided' influenced MNA significantly among hypertensive patients (Table 6). A study conducted in Brazil confirmed the high correlation between MNA and dissatisfaction with health services [60]. Hypertensive individuals who were dissatisfied with the care received in primary public health services (such as reception service, scheduling appointment and care received from the health team) were more likely to not adhere to the proposed medication treatment. Inconve-

Table 6. Variables summarised under the domain of health care services investigated by studies.

\begin{tabular}{|c|c|c|c|}
\hline $\begin{array}{c}\text { Variables being } \\
\text { investigated }\end{array}$ & Study & $\begin{array}{l}\text { Measurement of } \\
\text { medication } \\
\text { adherence }\end{array}$ & $\begin{array}{l}\text { Study setting and } \\
\text { sample size }\end{array}$ \\
\hline \multirow{4}{*}{$\begin{array}{l}\text { Dissatisfaction with } \\
\text { the health care } \\
\text { services received }\end{array}$} & Barreto et al. [60] & Morisky-Green test & Brazil; $N=68$ \\
\hline & Lubaki et al. [49] & Qualitative & Congo \\
\hline & Kusuma [58] & Qualitative & Delhi \\
\hline & Odusola et al. [40] & Qualitative & Nigeria \\
\hline $\begin{array}{l}\text { Inadequate } \\
\text { information from } \\
\text { health care Centre }\end{array}$ & Hussain et al. [34]. & Questionnaire & Bangladesh; $\mathrm{N}=120$ \\
\hline $\begin{array}{l}\text { Dissatisfaction } \\
\text { with treatment }\end{array}$ & $\begin{array}{c}\text { Al-Ramahi et al. } \\
{[38] .}\end{array}$ & MMAS 8 & Palestine; $\mathrm{N}=450$ \\
\hline $\begin{array}{l}\text { Fewer Interaction } \\
\text { with physicians }\end{array}$ & Hussain et al. [34] & Questionnaire & Bangladesh; $\mathrm{N}=120$ \\
\hline
\end{tabular}


nient clinic operating hours, long waiting time and under-dispensing of medications were found to be inhibitors of adherence in a qualitative study in Nigeria. Studies in Congo [49] and Delhi [58] found that antihypertensive medication were sometimes not readily available at health care centers. Patients waited for long periods to receive medications once they had been prescribed. Rude or unsympathetic behavior and attitudes by staff members at the health clinics was the other reason found for the dissatisfaction of the patients in Congo [49].

In Bangladesh, inadequate information from health care professionals about hypertension and its treatment $(\mathrm{AOR}=5.16 ; 95 \% \mathrm{CI} \%: 1.13$ - 23.66) were significantly associated with MNA [34]. Also in Palestine, patients dissatisfied with treatment were less likely to adhere to prescribed hypertensive medications than those satisfied with their treatments ( $\mathrm{AOR}=2.93$; 95\% CI: 1.22 - 7.02) [38]. Due to fewer interactions with the physicians, those receiving treatment at government hospitals had a 30 times greater chance of being non-adherent than those treated at private hospitals or clinics $(\mathrm{AOR}=35.29 ; 95 \%$ CI $9.76-127.63)$ in Bangladesh [34].

\subsection{Summary of the Result}

The results of the review provide insight into factors influencing MNA of hypertensive patients. Factors related to demography, barriers for adherence and treatment and disease related factors were the most commonly examined among the studies reviewed while factors related to perceptions regarding hypertension and its severity were the least examined. Associations of MNA with demographic and psychosocial factors such as age, gender, ethnicity, level of education, co-morbidities, duration of therapy, the number of medicines, use of social drugs, were often varied and not consistent. Factors affecting MNA consistently were: low socioeconomic status and low monthly income; family support; the use of traditional herbal preparations; knowledge and belief regarding hypertension and its management; cost of medications, avoiding side effect of medications; forgetfulness; absence of symptoms; distance from health facilities; irregular follow-up; and dissatisfaction with the treatment and health services provided.

\section{Discussion}

Though non-adherence to antihypertensive treatment is a significant problem in CHD management few studies on medication adherence have been conducted in developing countries [61]. Moreover, the majority of these studies were conducted in hospital and clinical settings. Studies carried out in low-income community settings are extremely limited.

Our review found that although there was substantial heterogeneity in methods and populations across studies, approximately half of the participated hypertensive population both male and female 18 years and older did not adhere properly to the treatment for hypertension as prescribed by their doctors. De- 
spite the higher prevalence of hypertension and its poor control among women in developing countries, we did not find any studies that focused specifically on this vulnerable population.Women in developing countries living with chronic non-communicable diseases such as hypertension experience particular challenges in accessing cost-effective prevention, early detection, diagnosis, treatment and care. The lack of knowledge and information regarding health, poor access to healthcare, family responsibilities, and poor economic, legal and political status further worsen their situation [62].

From 25 studies, we identified significant factors associated with MNA. A limitation of the selected studies was the fact that factors associated with MNA were not examined for gender differences. However, a study in Brazil reported reasons for non-adherence to medication and non-medication regimen in patients' opinion according to gender [63]. Considering the magnitude of inadequately treated or controlled hypertension among women in developing countries, studies that explore factors affecting MNA in this vulnerable population areurgently needed.

\subsection{Implications for Hypertension Management and Research}

The present review reveals that gender may not be a good predictor of non-adherence because of inconsistent conclusions. However, it is conceivable that women with low socioeconomic status and lower level of education are more vulnerable. Their lack of adherence might be due to their inability to buy medicines, and lack of access to free health facilities as governments in developing countries spends comparatively less of their budgets on health than developed countries. The importance of cost-related factors should be considered against the background of the relatively high out-of-pocket payments for most treatments in developing countries especially in South Asia and Africa.

The review also found that fear of side effects make some hypertensive patients stop their medications or reduce their daily doses without consulting their health care providers. Therefore, information tailored to patient's literacy level about the side effects of prescribed medications and how to manage these should be provided to all patients. From the review, it appears that educational level may not be a good predictor of MNA. However, sceptical attitudes towards antihypertensive treatment even among educated participants necessitate the health education on hypertension and its treatment to all hypertensive patients irrespective of the patients' educational status. Understanding potential complications of hypertension could be a motivating factor for adherence to treatment. For this to happen, patients need to be aware of the seriousness of their condition and all risks involved without being worried unnecessarily [64]. To better deal with these problems, educational interventions are required that recognise patients' apprehension and perceptions. In particular, patients should be provided an explanation of the benefits and adverse effects of treatment. The safety of long-term use of drugs needs to be discussed, including the information that treatment 
does not cause physical dependence irrespective of the length of treatment.

The review indicated that adherence to antihypertensive medication treatment would be improved if patients experience positive encounters with their doctors or health care providers regarding adequate and accurate advice on achieving control of their high blood pressure [65]. Among the selected studies, there was a general lack of assessment of individual risk perceptions of hypertension complications such as CHD. This is an unfortunate omission given the importance of such risk perceptions in medication adherence. Earlier studies in developed countries have shown that patients who accurately perceive their risk of cardiovascular disease are more likely to be adherent to medications and guidelines compared to those who do not perceive themselves to be at risk [66] [67] [68] [69]. Women's perceptions of their risk for heart disease can significantly influence their decision-making process concerning healthcare choice [70].

The studies in the review did not examine in depth cultural and psychological issues, in particular those relating to self-efficacy (i.e. the belief that one can perform a particular behavior under differing conditions which can greatly impact on medication adherence. Cultural restrictions make it difficult for women to seek medical care from male health care providers, [71] but there is, at the same time, a shortage of female health professionals [71]. These issues are compounded by health systems that often fail to respond to the particular needs of women with NCDs such as hypertension [72]. Weak health systems have been identified as a major obstacle in effectively responding to the rising burden of chronic conditions such as hypertension in developing countries. Studies are required that recognise and analyse the intricate associations between health systems and their effects on hypertension management in developing countries [73]. In spite of the need for research on health systems, little attention has also been given to the role of local health systems in the delivery of care for the control of hypertension. Moreover, belief-laden factors including confidence in the physician's knowledge or ability, belief of control over one's health and illness perception were all found to be significantly related to medication adherence in developed countries [74]. Studies in developing countries especially at community settings on these factors influencing adherence would be helpful to address the knowledge gap and contribute to global strategies for addressing non-compliance among hypertensive patients.

\subsection{Strengths and Weaknesses of the Review}

We have included studies from 20 developing countries (27.40\% of all developing countries). Having the study population from less than one third of the developing countries incorporated in the analysis, the conclusions of this review might not be extrapolated to the whole population of the developing countries.

Most of the studies in our review that met inclusion criteria were quantitative in type. Only half of the quantitative studies (20) chose study participants using simple or systematic random sampling techniques. Eight studies used purposive sampling method, thus their results may not be necessarily generalisable to the 
wider population. The remaining studies selected all eligible hypertensive patients from clinics/hospitals or communities as their study participants.

The review followed the PRISMA reporting guidelines for identifying, reporting, and synthesising research. The results of the review are robust. Most of studies selected for the review were judged to be of moderate to strong quality in terms of research rigour, reliability and validity. A large number of MNA related factors were consistently identified across different countries. However, this review was subject to a few limitations. This study included only English peer-reviewed journal articles. The majority of the studies relied solely on self-reported adherence, which may be subject to self-presentation and recall bias. Moreover, heterogeneity in important aspects of methodology of the selected studieslimits the results that can be drawn from the synthesis of the data.MNA may also be influenced by the time in which the study was performed.Among the selected quantitative studies, only two prospective cross-sectional studies were found. Longitudinal assessment is desirable to differentiate between chronic and occasional nonadherence and related barriers that may contribute to non-adherence.

\subsection{Conclusion}

This systematic review examined the prevalence of MNA among hypertensive population as well as investigated factors affecting MNA. Approximately half of hypertensive men and women were found to be non-adherent to their medications. Among the selected studies, very few studies were conducted in low-income community settings. MNA was influenced by a range of factors including socio-economic status, knowledge of hypertension and its management, medication side effects, costs of medication, and dissatisfaction with the treatment and health services provided. There was a general lack of consideration of cultural barriers, role of health system in health care delivery, self-efficacy, and perceived individual risk of hypertension complications. Policymakers and health service providers should take these factors into account to tailor culturally appropriate intervention strategies to enhance adherence among hypertensive patients. There is also a lack of gender-specific research which is necessary given the social and economic vulnerabilities faced by women in developing countries that may affect adherence to antihypertensive medications.

\section{Acknowledgements}

LD would like to acknowledge the Australian Postgraduate Award and Curtin University Research Scholarship for supporting her research that formed part of her PhD study.

\section{Author Contributions}

LD, JD, MA designed the study. LD Carried out the search, selected papers and extracted data. LD, JD, MA participated in data analysis and drafted the manuscript. All authors approved of the final version of the manuscript. 


\section{References}

[1] WHO (2014) World Health Statistics 2014 Report Geneva: World Health Organization. http://apps.who.int/iris/bitstream/10665/112738/1/9789240692671_eng.pdf.

[2] WHO (2011) World Health Statistics 2011. World Health Organization, Geneva.

[3] Boutayeb, A. and Boutayeb, S. (2005) The Burden of Non Communicable Diseases in Developing Countries. International Journal for Equity in Health, 4, 2. https://doi.org/10.1186/1475-9276-4-2

[4] WHO (2003) Adherence to Long-Term Therapies: Evidence for Action. World Health Organization, Geneva, 12-30.

[5] Thom, T., Haase, N., Rosamond, W., Howard, V.J., Rumsfeld, J., Manolio, T., et al. (2006) Heart Disease and Stroke Statistics-2006 Update: A Report from the American Heart Association Statistics Committee and Stroke Statistics Subcommittee. Circulation, 113, e85-e151. https://doi.org/10.1161/CIRCULATIONAHA.105.171600

[6] Alwan, A. (2011) Global Status Report on Non Communicable Diseases 2010. World Health Organization, Geneva. http://www.who.int/chp/countries/en/

[7] World Health Organization (2013) High Blood Pressure-Global and Regional Overview. WHO, Regional office for South East Asia.

[8] Gupta, P.C., Gupta, R. and Pendnekar, M.S. (2004) Hypertension Prevalence and Blood Pressure Trends in 88653 Subjects in Mumbai, India. Journal of Human Hypertension, 18, 853-856. https://doi.org/10.1038/sj.jhh.1001763

[9] Gupta, R., Guptha, S., Sharma, K.K., Gupta, A. and Deedwania, P. (2012) Regional Variations in Cardiovascular Risk Factors in India: India Heart Watch. World Journal of Cardiology, 4, 112-120. https://doi.org/10.4330/wjc.v4.i4.112

[10] Gupta, R., Gupta, V.P., Sarna, M., Prakash, H., Rastogi, S. and Gupta, K.D. (2003) Serial Epidemiological Surveys in an Urban Indian Population Demonstrate Increasing Coronary Risk Factors among the Lower Socioeconomic Strata. The Journal of the Association of Physicians of India, 51, 470-477.

[11] Lozano, R., Naghavi, M., Foreman, K., Lim, S., Shibuya, K., Aboyans, V., et al. (2012) Global and Regional Mortality from 235 Causes of Death for 20 Age Groups in 1990 and 2010: A Systematic Analysis for the Global Burden of Disease Study 2010. Lancet, 380, 2095-2128. https://doi.org/10.1016/S0140-6736(12)61728-0

[12] Rodgers, A., Lawes, C. and MacMahon, S. (2000) Reducing the Global Burden of Blood Pressure-Related Cardiovascular Disease. Journal of Hypertension Supplement. Official Journal of the International Society of Hypertension, 18, S3-S6.

[13] Pickering, T. (2001) Why Are We Doing So Badly with the Control of Hypertension? Poor Compliance Is Only Part of the Story. The Journal of Clinical Hypertension, 3, 179-182. https://doi.org/10.1111/j.1524-6175.2001.00465.x

[14] Lim, S.S., Vos, T., Flaxman, A.D., Danaei, G., Shibuya, K., Adair-Rohani, H., et al. (2012) A Comparative Risk Assessment of Burden of Disease and Injury Attributable to 67 Risk Factors and Risk Factor Clusters in 21 Regions, 1990-2010: A Systematic Analysis for the Global Burden of Disease Study 2010. Lancet, 380, 22242260. https://doi.org/10.1016/S0140-6736(12)61766-8

[15] Pereira, M., Lunet, N., Azevedo, A. and Barros, H. (2009) Differences in Prevalence, Awareness, Treatment and Control of Hypertension between Developing and Developed Countries. Journal of Hypertension, 27, 963-975. https://doi.org/10.1097/HJH.0b013e3283282f65

[16] Waeber, B., Burnier, M. and Brunner, H. (2000) How to Improve Adherence with 
Prescribed Treatment in Hypertensive Patients? Journal of Cardiovascular Pharmacology, 35, S23-S26.

[17] Cramer, J.A., Roy, A., Burrell, A., Fairchild, C.J., Fuldeore, M.J., Ollendorf, D.A., et al. (2008) Medication Compliance and Persistence: Terminology and Definitions. Value Health, 11, 44-47. https://doi.org/10.1111/j.1524-4733.2007.00213.x

[18] Bell, J.S., Airaksinen, M.S., Lyles, A., Chen, T.F. and Aslani, P. (2007) Concordance Is Not Synonymous with Compliance or Adherence. British Journal of Clinical Pharmacology, 64, 710-713. https://doi.org/10.1111/j.1365-2125.2007.02971_1.x

[19] Vrijens, B., Vincze, G., Kristanto, P., Urquhart, J. and Burnier, M. (2008) Adherence to Prescribed Antihypertensive Drug Treatments: Longitudinal Study of Electronically Compiled Dosing Histories. BMJ, 336, 1114-1117. https://doi.org/10.1136/bmj.39553.670231.25

[20] Mills, E.J., Nachega, J.B., Buchan, I., Orbinski, J., Attaran, A., Singh, S., et al. (2006) Adherence to Antiretroviral Therapy in Sub-Saharan Africa and North America: A Meta-Analysis. JAMA: The Journal of the American Medical Association, 296, 679690. https://doi.org/10.1001/jama.296.6.679

[21] Bangsberg, D.R., Hecht, F.M., Charlebois, E.D., Zolopa, A.R., Holodniy, M., Sheiner, L., et al. (2000) Adherence to Protease Inhibitors, HIV-1 Viral Load, and Development of Drug Resistance in an Indigent Population. AIDS, 14, 357-366. https://doi.org/10.1097/00002030-200003100-00008

[22] Natioal Collaborating Centre for Methods and Tools (2008) Quality Assessment Tool for Quantitative Studies. McMaster University, Hamilton.

[23] NICE (2012) Methods for the Development of NICE Public Health Guidance. 3rd Edition, National Institute for Health and Care Ecellence.

[24] Moher, D., Liberati, A., Tetzlaff, J. and Altman, D., The PRISMA Group (2009) Preferred Reporting Items for Systematic Reviews and Meta-Analyses: The PRISMA Statement PLoS Med.

[25] Osamor, P.E. and Owumi, B.E. (2011) Factors Associated with Treatment Compliance in Hypertension in Southwest Nigeria. Journal of Health, Population and Nutrition, 29, 619-628.

[26] Boima, V., Ademola, A.D., Odusola, A.O., Agyekum, F., Nwafor, C.E., Cole, H., et al. (2015) Factors Associated with Medication Nonadherence among Hypertensives in Ghana and Nigeria. International Journal of Hypertension, 205716. https://doi.org/10.1155/2015/205716

[27] Nagarkar, A.M., Gadhave, S.A., Sharma, I., Choure, A. and Morisky, D. (2013) Factors Influencing Medication Adherence among Hypertensive Patients in Atertiary Care Hospital, Pune, Maharastra. National Journal of Community Medicine, 4, 559563.

[28] Lalić, J., Radovanović, R.V., Mitić, B., Nikolić, V., Spasić, A. and Koraćević, G. (2013) Medication Adherence in Outpatients with Arterial Hypertension. Acta Facultatis Medicae Naissensis, 30, 209-218. https://doi.org/10.2478/afmnai-2013-0013

[29] Khanam, M.A., Lindeboom, W., Koehlmoos, T.L., Alam, D.S., Niessen, L. and Milton, A.H. (2014) Hypertension: Adherence to Treatment in Rural BangladeshFindings from a Population-Based Study. Glob Health Action, 7, 25028. https://doi.org/10.3402/gha.v7.25028

[30] Praveen, K.N. and Halesh, L.H. (2010) Antihypertensive Treatment: A Study on Correlates of Non Adherence in a Tertiary Care Facility. International Journal of Biological and Medical Research, 1, 248-252. 
[31] Ismael, D.H. and Qadir, S.C. (2015) Factors Affecting Treatment Compliance of Hypertensive Patients in Erbil City. Kufa Journal for Nursing Sciences, 5.

[32] Joho, A.A. (2012) Factors Affecting Treatment Compliance among Hypertension Patients in three District Hospitals-Dar es Salaam. Masters Thesis, Muhimbili University of Health and Allied Sciences.

[33] Bhandari, B., Bhattarai, M., Bhandari, M., Ghimire, A., Pokharel, P.K. and Morisky, D.E. (2015) Adherence to Antihypertensive Medications: Population Based Follow up in Eastern Nepal. Journal of Nepal Health Research Council, 13, 38-42.

[34] Hussain, S.M., Boonshuyar, C. and Ekram, A. (2011) Non-Adherence to Antihypertensive Treatment in Essential Hypertensive Patients in Rajshahi, Bangladesh. Anwer Khan Modern Medical College Journal, 2, 9-14.

[35] Gelaw, B.K., Gelaw, Y.K., Satessa, D.Ga. and G/Mariam, E.T. (2013) Assessment of Adherence of Patients with Anti-Hypertensive Medication and Factors for NonAdherence in Amhara Region Dessie Referral Hospital, Ethiopia. International Journal of Chemical and Natural Science, 2, 51-57.

[36] Hareri, H.A., Gedefaw, M. and Simeng, B. (2014) Assessment of Prevalence and Associated Factors of Adherence to Antihypertensive Agents among Adults on Follow up in Adama Referal Hospital, East Shoa, Ethiopia-Cross Sectional Study. International Journal of Current Microbiology and Applied Sciences, 3, 760-770.

[37] Ambaw, A.D., Alemie, G.A., W/Yohannes, M.S. and Mengesha, Z.B. (2012) Adherence to Antihypertensive Treatment and Associated Factors among Patients on Follow up at University of Gondar Hospital, Northwest Ethiopia. BMC Public Health, 12.

[38] Al-Ramahi, R. (2015) Adherence to Medications and Associated Factors: A CrossSectional Study among Palestinian Hypertensive Patients. Journal of Epidemiology and Global Health, 5, 125-132. https://doi.org/10.1016/j.jegh.2014.05.005

[39] Saleem, F., Hassali, M., Shafie, A. and Atif, M. (2012) Drug Attitude and Adherence: A Qualitative Insight of Patients with Hypertension. Journal of Young Pharmacists. JYP, 4, 101-107. https://doi.org/10.4103/0975-1483.96624

[40] Odusola, A.O., Hendriks, M., Schultsz, C., Bolarinwa, O.A., Akande, T., Osibogun, A., et al. (2014) Perceptions of Inhibitors and Facilitators for Adhering to Hypertension Treatment among Insured Patients in Rural Nigeria: A Qualitative Study. BMC Health Services Research, 14, 624. https://doi.org/10.1186/s12913-014-0624-z

[41] Nsitou, M.B., Stéphane, M., Bousso and Bwira, B. (2013) Patients-Related Predictors of Poor Adherence to Antihypertensive Treatment in Congo-Brazzaville: A CrossSectional Study. Global Journal of Medicine and Public Health, 2.

[42] Campbell, P.C. and Oladeyi, O.O. (2014) Compliance to and Knowledge of AntiHypertensive Therapy amongst Hypertensive Patients Attending Lagos University Teaching Hospital (Luth), Idi-Araba, Lagos, Nigeria. IOSR Journal of Dental and Medical Sciences, 13, 108-115. https://doi.org/10.9790/0853-1353108115

[43] Dennis, T., Meera, N.K., Binny, K., Sekhar, M.S., Kishore, G. and Sasidharan, S. (2011) Medication Adherence and Associated Barriers in Hypertension Management in India. CVD Prevention and Control, 6, 9-13. https://doi.org/10.1016/j.cvdpc.2010.11.001

[44] Bilal, A., Riaz, M., Shafiq, N., Ahmed, M., Sheikh, S. and Rasheed, S. (2015) NonCompliance to Anti-Hypertensive Medication and Its Associated Factors among Hypertensives. Journal of Ayub Medical College Abbottabad, 27, 158-163.

[45] Hareri, H.A. and Abebe, M. (2013) Assessments of Adherence to Hypertension Medications and Associated Factors among Patients Attending Tikur Anbessa Specia- 
lized Hospital Renal Unit, Addis Ababa, Ethiopia 2012. International Journal of Nursing Science, 3, 1-6.

[46] Ali, M., Bekele, M. and Teklay, G. (2014) Antihypertensive Medication Non-Adherence and Its Determinants among Patients on Follow up in Public Hospitals in Northern Ethiopia. International Journal of Clinical Trials, 1, 95. https://doi.org/10.5455/2349-3259.ijct20141103

[47] Olowookere, A., Olowookere, S., Talabi, A., Etonyeaku, A., Adeleke, O. and Akinboboye, O. (2015) Perceived Family Support and Factors Influencing Medication Adherence among Hypertensive Patients Attending a Nigerian Tertiary Hospital. Annals of Tropical Medicine and Public Health, 8, 245. https://doi.org/10.4103/1755-6783.162668

[48] Ahmed, S. (2015) Assessment of Adherence to Antihypertensive Treatment among Patients Attending a Health Care Facility in North India. International Journal of Research in Medicine, 4, 117-124.

[49] Fina Lubaki, J.-P., Mabuza, L., Malete, N., Maduna, P. and Mdimande, J. (2009) Reasons for Non-Compliance among Patients with Hypertension at Vanga Hospital, Bandundu Province, Democratic Republic of Congo: A Qualitative Study. African Journal of Primary Health Care \& Family Medicine, 1.

[50] Kamran, A., Sadeghieh, A.S., Biria, M., Malepour, A. and Heydari, H. (2014) Determinants of Patient's Adherence to Hypertension Medications: Application of Health Belief Model among Rural Patients. Annals of Medical and Health Sciences Research, 4, 922-926. https://doi.org/10.4103/2141-9248.144914

[51] Shima, R., Farizah, M.H. and Majid, H.A. (2014) A Qualitative Study on Hypertensive Care Behavior in Primary Health Care Settings in Malaysia. Patient Prefer Adherence, 8, 1597-1609. https://doi.org/10.2147/PPA.S69680

[52] Eizubier, A.G., Husain, A.A., Suleiman, A. and Hamid, Z.A. (2000) Drug Compliance among Hypertensive Patients in Kassala, Eastern Sudan. Eastern Mediterranean Health Journal, 6, 100-105.

[53] Srikanth, J. and Kulkarni, S. (2015) Hypertension in Elderly: Prevalence and Health Care Seeking Pattern in an Urban Slum of Bangalore City. International Journal of Recent Scientific Research, 6, 2952-2957.

[54] Ramli, A., Ahmad, N.S. and Paraidathathu, T. (2012) Medication Adherence among Hypertensive Patients of Primary Health Clinics in Malaysia. Patient Prefer Adherence, $6,613-622$

[55] Srivastava, A.K., Kandpal, S.D. and Sati, H. (2015) Predictors for Adherence in Hypertensive Therapy-A Study in Rural Area of District Dehradun. Indian Journal of Community Health, 27, 320-326.

[56] Hu, H., Li, G. and Arao, T. (2013) How Hypertensive Patients in the Rural Areas Use Home Blood Pressure Monitoring and Its Relationship with Medication Adherence: A Primary Care Survey in China. Open Journal of Preventive Medicine, 3, 510-516. https://doi.org/10.4236/ojpm.2013.39069

[57] Hashmi, S.K., Afridi, M.B., Abbas, K., Sajwani, R.A., Saleheen, D., Frossard, P.M., et al. (2007) Factors Associated with Adherence to Anti-Hypertensive Treatment in Pakistan. PLoS One, 2, e280. https://doi.org/10.1371/journal.pone.0000280

[58] Kusuma, Y.S. (2010) Migrants' Perception on Barriers to Treatment Seeking for Hypertension: a Qualitative Study from Delhi, India. Ethno Med, 4, 173-176.

[59] Barreto, Md.S., Reiners, A.A.O. and Marcon, S.S. (2014) Knowledge about Hypertension and Factors Associated with the Non-Adherence to Drug Therapy. Revista 
Latino-Americana de Enfermagem, 22, 491-498. https://doi.org/10.1590/0104-1169.3447.2442

[60] Silva Barreto, Md., Schiavon Ganassin, G., Matsuda, L.M. and Marcon, S.S. (2015) Dissatisfaction with the Health Service and Non-Adherence to Antihypertensive Medication Treatment in Brazil. Open Journal of Nursing, 5, 49-57. https://doi.org/10.4236/ojn.2015.51006

[61] Jin, J., Sklar, G.E., Min Sen Oh, V. and Li, S.C. (2008) Factors Affecting Therapeutic Compliance: A Review from the Patient's Perspective. Therapeutics and Clinical Risk Management, 4, 269-286. https://doi.org/10.2147/TCRM.S1458

[62] Chatterjee, C. and Sheoran, G. (2007) Vulnerable Groups in India. The Centre for Enquiry into Health and Allied Themes (CEHAT), Mumbai.

[63] Dosse, C., Cesarino, C., Martin, J. and Castedo, M. (2009) Factors Associated to Patients' Non Compliance with Hypertension Treatment. Latino-Am Enfermagem, 17, 201-206. https://doi.org/10.1590/S0104-11692009000200010

[64] Gadkari, A.S. and McHorney, C. (2012) Unintentional Non-Adherence to Chronic Prescription Medications: How Unintentional Is It Really? BMC Health Services Research, 12.

[65] Benson, J. and Britten, N. (2002) Patients' Decisions about Whether or Not to Take Antihypertensive Drugs: Qualitative Study. British Medical Journal, 325, 873-877. https://doi.org/10.1136/bmj.325.7369.873

[66] Kreuter, M.W. and Strecher, V.J. (1995) Changing Inaccurate Perceptions of Health Risk: Results from a Randomized Trial. Health Psychology, 14, 56-63.

https://doi.org/10.1037/0278-6133.14.1.56

[67] Van der Pligt, J. (1998) Perceived Risk and Vulnerability as Predictors of Precautionary Behavior. British Journal of Health Psychology, 3, 1-14. https://doi.org/10.1111/j.2044-8287.1998.tb00551.x

[68] Rimal, R.N. (2001) Perceived Risk and Self-Efficacy as Motivators: Understanding Individuals' Long Term Use of Health Information. Journal of Communication, 51, 633-654. https://doi.org/10.1111/j.1460-2466.2001.tb02900.x

[69] Weinstein, N.D. (1999) What Does It Mean to Understanding a Risk? Evaluating Risk Comprehension. J Natl Cancer Inst Monogr, 25, 15-20. https://doi.org/10.1093/oxfordjournals.jncimonographs.a024192

[70] Cioe, P.A. (2005) Women's Perceptions of Coronary Heart Disease-An Integrative Review. Journal of Cardiovascular Nursing, 20, 170-176.

https://doi.org/10.1097/00005082-200505000-00008

[71] Banglanews 490en-Xoom.it.

[72] Oti, S.O. (2013) HIV and Noncommunicable Diseases: A Case for Health System Building. Current Opinion in HIV and AIDS, 8, 65-69. https://doi.org/10.1097/COH.0b013e32835b8088

[73] Maimaris, W., Paty, J., Perel, P., Legido-Quigley, H., Balabanova, D., Nieuwlaat, R., et al. (2013) The Influence of Health Systems on Hypertension Awareness, Treatment, and Control: A Systematic Literature Review. PLoS Med, 10, e1001490. https://doi.org/10.1371/journal.pmed.1001490

[74] Chia, L.R., Schlenk, E.A. and Dunbar-Jacob, J. (2006) Effect of Personal and Cultural Beliefs on Medication Adherence in the Elderly. Drugs Aging, 23, 191-202. https://doi.org/10.2165/00002512-200623030-00002

[75] Venkatachalam, J., Abrahm, S.B., Singh, Z., Stalin, P. and Sathya, G.R. (2015) Determinants of Patient's Adherence to Hypertension Medications in a Rural Population of Kancheepuram District in Tamil Nadu, South India. Indian Journal of Com- 
munity Medicine, 40, 33-37. https://doi.org/10.4103/0970-0218.149267

[76] Kumar, N., Unnikrishnan, B., Thapar, R., Mithra, P., Kulkarni, V., Holla, R., et al. (2014) Factors Associated with Adherence to Antihypertensive Treatment among Patients Attending a Tertiary Care Hospital in Mangalore, South India. International Journal of Current Research and Review, 6, 77-85.

[77] Rao, B.B., Kabra, P.R. and Sreedhar, M. (2014) Factors Associated with Adherence to Antihypertensive Treatment among Hypertensive Persons in a Urban Slum Area of Hyderabad. Indian Journal of Basic and Applied Medical Research, 4, 471-477.

[78] Bhandari, S., Sarma, P.S. and Thankappan, K.R.P. (2011) Adherence to Antihypertensive Treatment and Its Determinants among Urban Slum Dwellers in Kolkata, India. Asia-Pacific Journal of Public Health/Asia-Pacific Academic Consortium for Public Health.

[79] Turki, A.K. and Sulaiman, S.A. (2009) Adherence to Antihypertensive Therapy in General Hospital of Penang: Does Daily Dose Frequency Matter? Jordan Journal of Pharmaceutical Sciences, 2.

[80] Atulomah, N.O., Florence, O.M. and Oluwatosin, A. (2010) Treatment Adherence and Risk of Non-Compliance among Hypertensives at a Teaching Hospital in Ogun State, Southwest Nigeria. Acta SATECH, 3, 143-149.

[81] Saleem, F., Hassali, M., Shafie, A., Awad, A. and Bashir, S. (2011) Association between Knowledge and Drug Adherence in Patients with Hypertension in Quetta, Pakistan. Tropical Journal of Pharmaceutical Research, 10, 125-132. https://doi.org/10.4314/tjpr.v10i2.66552

[82] Zyoud, H.S., Al-Jabi, W.S., Sweileh, M.W. and Morisky, E.D. (2013) Relationship of Treatment Satisfaction to Medication Adherence: Findings from a Cross-Sectional Survey among Hypertensive Patients in Palestine. Health and Quality of Life Outcomes, 11, 191. https://doi.org/10.1186/1477-7525-11-191

[83] Edo, T.A. (2009) Factors Affecting Compliance with Anti Hypertensive Drug Treatment and Required Lifestyle Modifications among Hypertensive Patients on Praslin Island. Masters Thesis, University of South Africa, South Africa.

[84] Bovet, P., Burnier, M., Madeleine, G., Waeber, B. and Paccaud, F. (2002) Monitoring One-Year Compliance to Antihypertension Medication in the Seychelles. Bulletin of the World Health Organization, 80, 33-39.

[85] Mukora-Mutseyekwa, F.N. and Chadambuka, E.M. (2013) Drug Adherence Behavior among Hypertensive Out-Patients at a Tertiary Health Institution in Manicaland Province, Zimbabwe, 2011. Patient Prefer Adherence, 7, 65-70. https://doi.org/10.2147/PPA.S40295 


\section{Appendix}

Table A1. Overview and statistics details of the included studies.

\begin{tabular}{|c|c|c|c|c|c|c|c|}
\hline $\begin{array}{c}\text { Author and } \\
\text { year }\end{array}$ & Country & Study aim & $\begin{array}{l}\text { Sampling } \\
\text { method and } \\
\text { patient } \\
\text { population }\end{array}$ & $\begin{array}{c}\% \\
\text { women }\end{array}$ & Design & $\begin{array}{l}\text { Prevalence of } \\
\text { MNA (\%) } \\
\text { and \% of } \\
\text { female not } \\
\text { adhering }\end{array}$ & $\begin{array}{c}\text { Factors associated } \\
\text { with } \\
\text { medication } \\
\text { adherence/MNA }\end{array}$ \\
\hline $\begin{array}{l}\text { 1. Khanam et al. } \\
2014 \text { [29] }\end{array}$ & Bangladesh & $\begin{array}{l}\text { To describe } \\
\text { hypertension } \\
\text { and factors } \\
\text { affecting } \\
\text { adherence to } \\
\text { treatment } \\
\text { among } \\
\text { hypertensive } \\
\text { person }\end{array}$ & $\begin{array}{c}\mathrm{N}=29,960 \\
\text { Stratified two } \\
\text { stage sampling } \\
\text { from the } \\
\text { population } \\
\text { of three } \\
\text { rural sites }\end{array}$ & 52.6 & Cross-sectional & $26 /-$ & $\begin{array}{c}\text { Factors associated } \\
\text { with MNA: } \\
\text { male sex (AOR = 1.67; } \\
\text { 95\% CI: } 1.42-1.97), \\
\text { hypertension } \\
\text { diagnosed by } \\
\text { unqualified } \\
\text { providers (AOR = 1.52: } \\
\text { 95\% CI: } 1.31-1.77), \\
\text { and patients with } \\
\text { cardiovascular } \\
\text { comorbidity } \\
\text { (OR = 0.79; } \\
\text { 95\% CI: } 0.64-0.97) .\end{array}$ \\
\hline $\begin{array}{l}\text { 2. Hussain et al. } \\
\qquad 2011 \text { [34] }\end{array}$ & Bangladesh & $\begin{array}{l}\text { To identify } \\
\text { factors that } \\
\text { influence } \\
\text { non-adherence to } \\
\text { antihypertensive } \\
\text { therapy }\end{array}$ & $\begin{array}{c}\mathrm{N}=120 \\
\text { Simple random } \\
\text { sampling from } \\
\text { eligible } \\
\text { hypertensive } \\
\text { patients of } \\
\text { inpatient } \\
\text { departments } \\
\text { of a medical } \\
\text { college and a } \\
\text { private clinic }\end{array}$ & 30.8 & Cross-section & $85 /-$ & $\begin{array}{c}\text { Factors determining } \\
\text { MNA: lower level of } \\
\text { education (OR = 6.34; } \\
\text { 95\% CI: } 1.65 \text { - 24.41), } \\
\text { low family income } \\
\text { (OR = 11.60; } \\
\text { 95\% CI: } 3.77 \text { - 35.65), } \\
\text { poor Knowledge } \\
\text { levels regarding } \\
\text { management and } \\
\text { consequence of } \\
\text { untreated hypertension } \\
\text { (OR = 24.50; } \\
\text { 95\% CI: } 6.28 \text { - 95.58), } \\
\text { believes and } \\
\text { understanding of } \\
\text { disease (OR = 12.90; } \\
\text { 95\% CI: } 1.65 \text { - 100.63), } \\
\text { lack of accompanying } \\
\text { person to go to the } \\
\text { physician/hospital } \\
\text { (OR = 3.54; } \\
\text { 95\% CI:1.04 - 11.99), } \\
\text { deficiencies in } \\
\text { information } \\
\text { from service } \\
\text { provider } \\
\text { (OR = 5.16; } 95 \% \text { CI\%: } \\
\text { 1.13 - } 23.66) \text { and } \\
\text { government } \\
\text { hospital (OR = 35.29; } \\
95 \% \text { CI: } 9.76 \text { - 127.63). }\end{array}$ \\
\hline
\end{tabular}




\section{Continued}

$\begin{array}{ccc}\begin{array}{l}\text { 3. Barreto et al. } \\ 2015 \text { [59] }\end{array} & \begin{array}{c}\text { dissatisfaction } \\ \text { with the public } \\ \text { health service } \\ \text { and MNA to } \\ \text { antihypertensive }\end{array} & \begin{array}{c}\text { and stratified } \\ \text { way from } \\ \text { eligible } \\ \text { therapy. }\end{array} \\ & \begin{array}{c}\text { outients in } \\ \text { of primary } \\ \text { health care }\end{array}\end{array}$

4. Dosse et al. 2009 [63]

5. Hu et al. 2013 [56]

To determine attendance of patients to medical appointments; the $\%$ medication and non-medication regimens, and main reasons of hypertensive patients report for MNA

To explore how and why patients adopt home blood pressure monitoring (HBPM) and
$\mathrm{N}=392$

To investigate the association

between

dissatisfaction

ith the public

health service

therapy.

selected

ay from
60

Cross-sectional

$42.1 /$

Hypertensive

patients were

randomly

ton

(n)
Factors associated with MNA: dissatisfaction with the health

services: reception service $(\mathrm{OR}=1.6$; 95\%CI:1.08 - 2.46; $\mathrm{p}=0.01)$, scheduling appointment $(\mathrm{OR}=2.1$;

95\% CI:1.31 - 3.29;

$\mathrm{p}=0.000)$, care

received from

the health team

$$
(\mathrm{OR}=3.8 \text {; }
$$

95\% CI: 2.24 - 6.45;

$\mathrm{p}=0.000)$, solvability

of health problems

$(\mathrm{OR}=5.4$;

95\% CI: 3.08 - 9.56;

$\mathrm{p}=0.00)$, group

activities $(\mathrm{OR}=4.7$;

95\% CI: 2.77 - 7.81;

$\mathrm{p}=0.00)$ and

physician professional

$(\mathrm{OR}=6.5$;

95\% CI: 3.47 - 12.3;

$$
\mathrm{p}=0.00)
$$

of adherence to also identify the examine the association

between

HBPM and medication
$\mathrm{N}=68$

Hypertensive patients

registered in the outpatient clinic

of a teaching hospital

64.71 Cross-sectional

$86.76 /$

Main reasons reported for MNA: emotional factor (69.1\%), could not tell the reason $(10.3 \%)$ and eating habits $(8.8 \%)$. Statistically significant relation between men and women-reasons reported: could not tell the reason $(\mathrm{p}=0.006)$, alcohol consumption ( $p=0.013$ ), and associated disease

$$
(\mathrm{p}=0.049)
$$

Risk factors of MNA: shorter duration of hypertension $(\mathrm{AOR}=3.31$;

95\% CI: 1.91 - 5.72;$$
\mathrm{N}=318
$$
hypertensive patients from a

71.7 Cross-sectional $38.67 / 38.59$ $\mathrm{p}<0.001)$ and less frequency in performing $\mathrm{BP}$

measurements

$(\mathrm{AOR}=2.33$

95\% CI: 1.42 - 3.83; $\mathrm{p}<0.001)$ 


\section{Continued}

6. Nsitou et al. 2013 [41]

7. Fina Lubaki et al. 2009 [49]

$\begin{array}{cc}\begin{array}{c}\text { To assess the level } \\ \text { of compliance in } \\ \text { hypertensive }\end{array} & \begin{array}{c}\mathrm{N}=212 \\ \text { Eligible } \\ \text { hytients and }\end{array} \\ \begin{array}{c}\text { patients of } \\ \text { identify }\end{array} & \begin{array}{c}\text { outpatient } \\ \text { departments }\end{array} \\ \text { patients-related } \\ \text { predictors of MNA } & \begin{array}{c}\text { of three urban } \\ \text { hospital }\end{array}\end{array}$

57.5

Prospective

cross-sectional

$32.5 / 27.86$

Patient related predictors that could predict poor adherence by bivariate analysis: no Knowledge

of the treatment

$(\mathrm{OR}=4.16 ; 95 \%$

CI; 2.25 - 7.68;

$\mathrm{p} \leq 10^{-5}$ ) no knowledge of high BP related complications $(\mathrm{OR}=2.9$; 95\% CI: 1.61 - 5.29; $\mathrm{p}=0.000$ ), other pays for the medicine

$(\mathrm{OR}=2.17$;

95\% CI:1.20 - 3.92;

$\mathrm{p}=0.009)$, no

Knowledge of the severity of hypertension $(\mathrm{OR}=3.25$; 95\% CI: 1.5 - 7.02; $\mathrm{p}=0.001)$, costly medication $(\mathrm{OR}=0.42$; 95\% CI: 0.23 - 0.76; $\mathrm{p}=0.004)$, no tensinometer for self-monitoring

$(\mathrm{OR}=3.16$;

95\% CI: 1.44 - 6.92; $\mathrm{p}=0.002)$ and not existence of family member to remind to take medication

$(\mathrm{OR}=0.52$;

95\% CI: $0.29-0.93$ )

$\mathrm{p}=0.03$. After adjustment by logistic regression, statistically significant association with poor compliance: knowledge of the treatment $(\mathrm{p}=0.0170)$ and perception of the severity of complication $(\mathrm{p}=0.0373)$

$\mathrm{N}=3$ focus groups.

To explore reasons Purposive for MNA among sampling from patients with hypertension hypertensive patients of a cardiovascular clinic
Major causes of MNA side effects of the medications,
Qualitative study/Focus group interviews lack of information and support, difficulty in obtaining the medication and fact that the disease is mainly silent. 


\section{Continued}

9. Ali et al.

2014 [46]

10. Gelaw et al. 2013 [35]
To investigate antihypertensive medication

Ethiopia

non-adherence and its

determinants among patients

$\mathrm{N}=121$

All eligible hypertensive patients from outpatients of two referral hospitals

$$
\mathrm{N}=91
$$

To assess the Purposive adherence of the patients to Ethiopia anti-hypertensive medication and

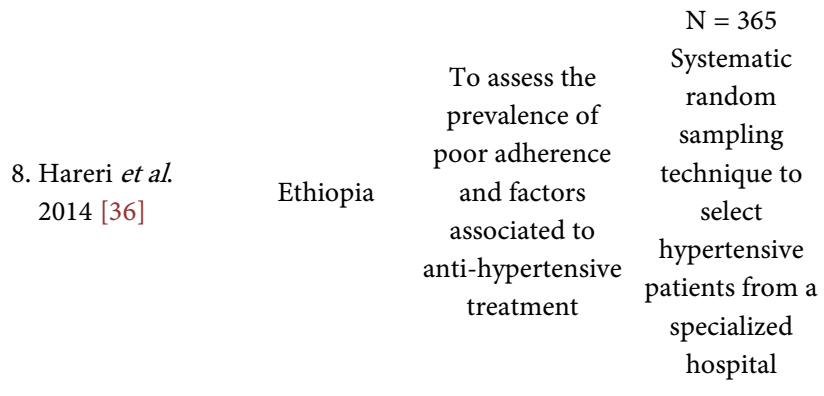

51.2 Cross-sectional 40.5

62

Prospective cross-sectional

26.4 main risk factors contributing to MNA sampling was conducted among eligible hypertensive patients who attended a referral Hospital during the study period
Factors hinder adherence: age group (46 - 55)

$$
(\mathrm{AOR}=0.30
$$

95\% CI: 0.142 - 0.640), lack of medication information

$$
(\mathrm{AOR}=0.12 \text {; }
$$

95\% CI: $0.258-0.583$ )

and presence of co-morbidities $(\mathrm{AOR}=0.50$ 95\% CI: 0.290 - 0.893). Muslim followers were 3 times more likely to be adherent to their treatment $(\mathrm{AOR}=3.20$; 95\% CI:1.69 - 6.08)

Factors significantly associated with MNA: family support $(\mathrm{AOR}=0.170$; 95\% CI: 0.030 - 0.905); spot blood pressure (AOR $=0.052$, 95\% CI: 0.003 - 0.242), place of patient residence (AOR = 0.184; 5\% CI: $0.024-0.597)$ and hypertension related complications $(\mathrm{AOR}=21.73$; 95\% CI: 1.568 - 418.42)

Factors contributed to MNA significantly: economic problems $(\mathrm{p}=0.04)$, less awareness about hypertension and its treatment $(\mathrm{p}<0.01)$, social drug use $(\mathrm{p}<0.01)$.

Other factors were distance, forget fullness, insufficient information about the effect of MNA and adverse effect understanding 
11. Hareri et al. 2013 [45]

12. Ambaw et al. 2012 [37]

13. Boima et al. 2015 [26]
Ethiopia

factors associated

with it among

hypertensive

patients

$$
\mathrm{N}=286
$$

Systematic

$$
\text { random }
$$

technique was

used to selected

$$
\text { eligible }
$$

hypertensive

patient from a

specialised

hospital

$\mathrm{N}=384$

Systematic

random

sampling

technique to

select patients

from an

university

teaching

hospital
57.7

7 Cross-sectional 30.8/59.1

63

Cross-sectional $\quad 35.4 / 33.5$

factors among

hypertensive

patients on

follow up
To determine

factors associated

Ghana and

Nigeria with

MNA among

hypertensive

patients
$\mathrm{N}=357$

All eligible

patients were

recruited from

four hospitals

from Ghana

and Nigeria
Respondents less likely to adhere to medication who had: private business

$(\mathrm{AOR}=0.28$,

95\% CI: 0.130 - 0.606;

$\mathrm{p}=0.001)$ and duration of diagnosis of five or more years $(\mathrm{AOR}=0.11 ; 95 \% \mathrm{CI}$ :

$0.01-0.95 ; \mathrm{p}=0.045)$.

Respondents more likely to adhere to anti-hypertensive medication: who were married $(\mathrm{AOR}=2.00 ; 95 \%$ CI: 1.33 - 6.74), attended most of the time private clinic to receive health care $(\mathrm{AOR}=6.34 ; 95 \% \mathrm{CI}$ : 1.17 - 33.96), treatment duration two to four years (AOR = 3.81; 95\% CI:

$1.26-11.51)$ and who were motivated $(\mathrm{AOR}=2.84$;

95\% CI: 1.47 - 5.43)

Variables, significantly associated with treatment adherence: female sex $(\mathrm{AOR}=0.48 ; 95 \%$ CI: $0.28-0.82)$, knowledgeable about hypertension and its treatment $(\mathrm{AOR}=6.21$; 95\% CI: 3.22 - 11.97),

decreased distance from the hospital (AOR = 2.02; 95\% CI: 1.19 - 3.43), having no or one co morbidity

$(\mathrm{AOR}=2.5$;

95\% CI: $1.01-6.21)$ and who have controlled hypertension $(\mathrm{AOR}=2.93$;

95\% CI: 1.73 - 4.96)

Adherence showed association with concern about medications ( $r=-0.0347, \mathrm{p}=0.002$ ) and knowledge of hypertension $(r=0.14, \mathrm{p}=0.006)$. MNA was related with:

57.5 Cross sectional 66.7/65.4 depression $(r=-0.208$, $\mathrm{p}<0.001)$, formal education $(\mathrm{p}=0.001)$, younger age $(p=0.000)$, use of herbal preparation $(\mathrm{p}=0.014)$, insured participants $(\mathrm{p}=0.032)$ and poor BP control $(p=0.006)$. 


\section{Continued}

14. Srivastava et al. 2015 [55]

15. Srikanth et al. 2015 [53]

16. Venkatachalam et al. 2015 [75]

17. Kumar et al. 2014 [76]
India

India
To study the factors

determining

adherence to

antihypertensive medication

$$
\mathrm{N}=304
$$

All elderly individuals $>60$ years residing in

66.7 Cross-sectional $38.6 /-$ an urban slum.

$\mathrm{N}=473$ hypertensive individual willing to participate from a community.
All eligible
52.2 Cross-sectional 75.89/74.5

\subsection{Cross sectional \\ $27 / 30.8$}

Older people was found to be significantly and independently associated with better adherence.

Patients on mono therapy were less adherent compared to those on two or three drugs. Patients who were aware of the association between certain risk factors for hypertension had better adherence.

Pearson's Chi square test showed significant association $(\mathrm{p}<0.005)$ between compliance to medication and number of drugs consumed. With increase in number of drugs to be consumed, the adherence to medication decreased $(\mathrm{p}=0.039)$

The participants exhibited poor adherence with lifestyle factors like unrestricted meal habits $(\mathrm{OR}=4.8)$, alcohol consumption $(\mathrm{OR}=3.1)$, smoking $(\mathrm{OR}=12.9)$, and salt intake $>5 \mathrm{gm}$

$(\mathrm{OR}=3.6)$. Adherence was significantly higher among respondents taking only one medication and once daily compared with individuals taking four types of medication and as frequent as three or more times a day.

Factors significantly associated with good adherence: absence of

To assess the level $\mathrm{N}=120$

All eligible consenting hypertensive patients of adherence and the factors influencing attending medicine outpatient department and hypertensive peripheral outreach clinic of a medical college side-effects (OR $=0.1 ; 95 \%$

CI: $0.03-0.52 ; \mathrm{p}=0.003$ )

availability of free medication $(\mathrm{OR}=0.4 ; 95 \%$ CI: $0.2-0.9 ; \mathrm{p}=0.030)$ and regular checkup of $\mathrm{BP}$

$$
(\mathrm{OR}=0.5 \text {; }
$$

95\% CI: 0.2 - 0.9;

$$
\mathrm{p}=0.034)
$$


18. Rao et al. 2014 [77]

19. Nagarkar et al. 2013 [27]

\section{Ahmad, S.} 2013 [48]

India

\author{
To assess \\ adherence to \\ antihypertensive \\ therapy and to \\ assess associated \\ factors for \\ adherence \\ among \\ hypertensive \\ patients
}

\section{To translate \\ and validate MMAS- 8 and to determine association between patient characteristics and medicine adherence in hypertension \\ $\mathrm{N}=174$ \\ Randomly selected hypertensive patients attending medicine outpatients of a district hospital}

44.87 Cross-sectional $\quad 76.5 / 70.7$

59.1 Cross-sectional $\quad 39.4 / 35.8$

Factors contributed to treatment adherence significantly $(\mathrm{p}<0.05)$ : patient $>60$ years of age $(67.2 \%)$ $(\mathrm{OR}=1.91$; 95\% CI: 3.40 - 1.08), married people

(84.7\%) $(\mathrm{OR}=3.45 ; 95 \%$

CI: 8.43 - 1.37); nonsmokers $(74.8 \%)$ $(\mathrm{OR}=3.83$; 95\% CI: 7.01 - 2.12), non-tobacco users $(68.9 \%)(\mathrm{OR}=6.36$; 95\% CI: 14.63 - 2.93) and people consuming 1 tablet a day $(67.7 \%)(\mathrm{OR}=2.26$; 95\% CI: 4.11 - 1.26)

MNA was significantly associated with patients $(\mathrm{p}<0.05)$ : age less than 57 year $(\mathrm{OR}=3.348$;

95\% CI: 1.665 - 6.732), living in nuclear family setup $(\mathrm{OR}=2.670$; 95\% CI: 1.378 - 5.175) and not experience of symptoms of hypertension $(\mathrm{OR}=0.414$; 95\% CI: 0.192 - 0.892)

Good adherence to treatment was present more among males

$\mathrm{N}=334$

Purposive

To assess the level of adherence and associated factors to antihypertensive treatment sampling of hypertensive patients reporting to a urban health and training centre
41.6 Cross-sectional 42.8/53.95
$(\mathrm{OR}=1.25)$ and in those patients who were either receiving one medicine per day $(\mathrm{OR}=4.27)$, or taking medicine once a day $(\mathrm{OR}=$ 1.96). Poor adherence to anti-hypertensive treatment was seen in patients with the habit of alcohol consumption ( $\mathrm{OR}=0.52)$, tobacco chewing

$(\mathrm{OR}=0.73)$ and smoking $(\mathrm{OR}=0.40)$ 


\section{Continued}

21. Bhandari, S. 2011 [78]

22. Dennis et al. 2010 [43]
To determine the prevalence and predictors of adherence

to modern antihypertensive pharmacotherapy

$$
\mathrm{N}=348
$$

All the eligible hypertensive patients living in a selected urban slum
68

Cross-sectional
$\mathrm{N}=608$

To assess Randomly

medication adherence in hypertensive India

\section{selected}

patients and to identify the main barriers associated with medication adherence. hypertensive

patients from

the outpatient of 48.68 Cross-sectional internal

medicine

department

of a teaching

hospital
Factors significantly associated with adherence ( $\mathrm{p}<0.05)$ : duration of hypertension

for $\geq 5$ years

$(\mathrm{AOR}=2.98$;

95\% CI: 1.73 - 5.14),

hypertension was detected during checkups for conditions related to hypertension $(\mathrm{AOR}=2.35$; 95\% CI: 1.25 - 4.39), living with $\leq 4$ family members $(\mathrm{AOR}=2.01$; 95\% CI: 1.52 - 3.50),

family income of $\geq 3000$ rupees $(\mathrm{AOR}=2.56 ; 95 \%$

CI: 1.47 - 4.45), getting free drugs $(\mathrm{AOR}=4.16: 95 \%$

CI: 1.36 - 12.69), perceived BP under control

$$
(\mathrm{AOR}=2.23 \text { : }
$$

95\% CI: 1.17 - 4.26) and satisfied with current treatment $(\mathrm{AOR}=3.77$; 95\% CI: 1.32 - 10.76)

Belief barrier was reported in $39.14 \%$ patients. Access barrier and recall barrier were reported by $82.57 \%$ and $62.17 \%$, respectively. $78.62 \%$ of patients reported that it is difficult to pay for the medication and 54.93\% indicated that it is difficult to get a refill timely. Logistic regression analysis showed that the education level was not contributing

to non-adherence $(\mathrm{OR}=0.75$, 95\% CI: $0.64-0.87$ ). However, duration of hypertension, $(\mathrm{p}=0.031)$ showed a significant contributory effect to MNA ( $p=0.031)$. Chi square analysis showed no relation between the adherence pattern and the number of antihypertensive medications being prescribed. 
23. Praveen et al. 2010 [30]

24. Kusuma, Y. S 2010 [58]

25. Kamran et al. 2014 [50]
$\mathrm{N}=804$

All eligible

To determine

factors that are

associated with

non-adherence to

antihypertensive

treatment

hypertensive

patient from the

outpatients of

General

$70 \%$ Cross-sectional

$29 / 34.5$

Medicine

of a tertiary

care hospital department

Factors

independently

associated with MNA

$(\mathrm{p}<0.05)$ : female sex

$(\mathrm{OR}=2.95$,

95\% CI:

$1.39-6.24)$, not

understand drug

regimen well

$(\mathrm{OR}=4.06$

95\% CI: 1.01 - 16.32),

affordability

to only some/none

of prescribed drugs

$(\mathrm{OR}=3.70$

95\% CI: 1.8 - 7.59) and

longer time since

last visit to a health

care facility $(\mathrm{OR}=7.26$;

95\% CI: 2.65 - 19.86)

To gain insights

into the

perceptions of

socio-economically

$\mathrm{N}=14$ key

informants and 3

migrants in focus groups.

elhi regarding Purposive

treatment

sampling from a

seeking

community

behaviour for

hypertension

Qualitative

Treatment seeking for

hypertension was not

adequate. Several

patient- and

provider-related

issues have emerged as

barriers in treatment

seeking and adherence.

MNA was

significantly associated with:

unrestricted

meal habits

$(\mathrm{OR}=4.8$;

95\% CI: 37.5),

$\mathrm{N}=671$

Two stage

To determine the

random

factors of sampling

adherence to methods to

hypertension select eligible

74.81 Cross-sectional 76/75.3

moking $(\mathrm{OR}=1.9$;

95\% CI: 1.3 - 2.9)

and salt

intake $>5 \mathrm{~g}$

$(\mathrm{OR}=19.7$;

95\% CI: 12.2 - 31.7)

Respondents with

regular physical

activity and

non-smokers

were more

adherent to

medication when

compared to

respondents with

sedentary lifestyle and

smoking $(\mathrm{p}<0.01)$. 


\section{Continued}

$\begin{array}{ccc}\begin{array}{c}\text { 26. Ismael } \text { et al. } \\ 2015[31]\end{array} & \begin{array}{c}\text { treatment and } \\ \text { identified factors } \\ \text { contributing to } \\ \text { poor compliance }\end{array} & \begin{array}{c}\text { participants } \\ \text { among all } \\ \text { hypertensive } \\ \text { patients in a }\end{array} \\ & & \begin{array}{c}\text { general } \\ \text { teaching } \\ \end{array} \\ & \text { hospital }\end{array}$

27. Shima et al. 2013 [51]

28. Ramli et al. 2012 [54]
To explore patients' experiences with their illnesses and the reasons which influenced them in not following hypertensive care recommendations
$\mathrm{N}=653$ Random sampling adherence to medications by adult patients
$\mathrm{N}=200$

Purposive

sampling was

To assess the level of compliance to treatment and identified factors contributing to poor compliance

hospital

$$
\mathrm{N}=2
$$

Purposive sampling from patients attending follow-up at primary health clinics Qualitative undergoing hypertensive treatment method to select hypertensive patients from 7 care clinics primary health
Major factor for MNA was

forgetfulness. There was a significant association between high level of adherence and age group of $>65$ years $(\mathrm{p}=0.000)$, male gender $(p=0.003)$, no formal education $(\mathrm{p}=0.000)$, and duration of hypertension less than 10 years $(\mathrm{p}=0.003)$. Also there was significant relation between adherence and benefit of treatment, barrier of treatment, severity of disease, susceptibility to complication and reminder by advice from nurses (strongest predictor)

Most of the reasons given for not taking antihypertensive medication were side effects or fear of the side effects of antihypertensive medication, patients' attitudes, lack of information from health care professionals and insufficient social support

Female patients were found to be more likely to be adherent than male patients

$$
(\mathrm{OR}=1.38 \text {; }
$$

95\% CI: 1.00 - 1.90; $\mathrm{p}=0.05])$. Patients from the Malay ( $\mathrm{OR}=1.68 ; 95 \%$ CI: 1.03 - 2.73) and Chinese ethnic group $(\mathrm{OR}=2.64$; 95\% CI: 1.52 - 4.58) were also more likely to adhere, compared to patients from the Indian subgroups. The mean number of drugs that patients were taking was higher in non-adherers (3.67) than in adherers $(3.17$ [ $\mathrm{t}=3.81, \mathrm{df}=651$;

$$
\mathrm{p}=0.001])
$$




\section{Continued}

29. Turki. et al. 2009 [79]

30. Bhandari et al. 2015 [33]

31. Olowookere et al. 2015 [47]
To identify

patients with poor

adherence

toantihypertensive

therapy and

Malaysia

compare the levels of adherence with daily dose

frequency of antihypertensive therapy

\section{$\mathrm{N}=518$}

Convenience

sampling to

select

hypertensive

patients from a

clinic of a

general hospital
42.6 Cross-sectional

$\mathrm{N}=154$

Participants

To explore the extent of

adherence towards prescribed

antihypertensive treatment and to elucidate the factors of MNA

\section{were selected}

from all the

diagnosed

hypertensive patients of a selected community by simple random sampling method
Cross-sectional
$43.5 / 54.2$

$\mathrm{N}=420$

To assess perceived family support and other factors that determine medication adherence among hypertensive patients
Adult patients

$$
\text { on }
$$

antihypertensive

medications attending a

medical

outpatient

clinic
Study found a

significant relationship between daily dose frequency groups and adherence at level $\mathrm{p}<0.001$. It shows that that who have more daily dose frequency, will show higher level of

adherence towards antihypertensive medications

Predictors of MNA by logistic regression analysis $(\mathrm{p}<0.05)$ :

Illiteracy

$(\mathrm{OR}=5.34$;

95\% CI: 1.23 - 23),

price of medicine $(\mathrm{OR}=5.14$;

95\% CI: 1.1 - 23.9), missed medicine

due to cost $(\mathrm{OR}=0.143$;

95\% CI: 0.02 - 0.78)

no family history of hypertension $(\mathrm{OR}=4.46$,

95\% CI: 1.21 - 16.4), irregular follow up $(\mathrm{OR}=6.39$ :

95\% CI: 1.22 - 33.3) and more than one pills per day $(\mathrm{OR}=5.33$;

95\% CI: 1.19 - 23.7)

Common reasons for MNA include belief of cure (43\%), high cost of treatment (33\%), and the experiencing of side effects (27\%).

Patients with good family support had better adherence compared to those with poor family support $(\mathrm{p}<0.05)$. MNA was higher among newly diagnosed hypertensive patients, those with higher pill burden, and those without family support $(\mathrm{p}<0.05)$. 


\section{Continued}

32. Campbell et al. 2014 [42]

33. Odusola et al. 2014 [40]

Nigeria

mpliance and

knowledge of

antihypertensive

$\mathrm{N}=262$

Multistage

sampling

technique was

used to select

the eligible

hypertensive

patients from

hypertension

clinic therapy amongst

outpatients

attending a

hypertensive

clinic

outpatients of a

52.6 Cross-sectional $74.81 / 78.83$

$\mathrm{N}=40$

hypertension

management.
To explore patients views on

Purposive

Nigeria sampling from

a rural

primary

health care
The significant reasons for MNA

$(\mathrm{p}<0.05)$ :

forgetfulness

$(\mathrm{OR}=14.8$;

95\% CI: 3.9 - 54.8); ran

out of prescribed

drugs (OR = 1.3;

95\% CI: 0.1 - 0.4);

avoiding side effects

$(\mathrm{OR}=3.0$;

95\% CI: 1.4 - 6.7)

and absence of

symptoms $(\mathrm{OR}=3.3$;

95\% CI: 1.3 - 8.0).

Factors significantly associated

with adherence to antihypertensive

treatment: religion

$(\mathrm{X} 2=5.0068, \mathrm{df}=1$

$\mathrm{p}=0.025)$ and

knowledge

(X2 = 6.6848;

$\mathrm{df}=1, \mathrm{p}=0.0097$;

F-exact test $=0.0184$ )

Facilitators of

medication

adherence included

affordability of care

(through health

insurance), trust

in orthodox "western"

medicines, trust

in doctor, dreaded dangers of

hypertension, and use of prayer to support efficacy of pills. Inhibitors of medication adherence included inconvenient clinic operating hours, long waiting times, under-dispensing of prescriptions, side-effects of pills, faith motivated changes of medication regimen, herbal supplementation/ substitution of pills, and ignorance that regular use is needed. Local practices and norms were identified as important inhibitors to the uptake of healthier behaviours. 
34. Osamor et al. 2011 [25]

35. Atulomah et al. 2010 [80] 36. Bilal et al.
2015 [44]

37. Saleem et al. 2012 [39]
Nigeria

To investigate the factors associate with self-reported compliance among hypertensive subjects in a poor urban community

To collect

information about perceived severity and threat to life from poor

Nigeria treatment response and medication adherence in hypertensive people

To determine the frequency and factors

Pakistan associated with non-compliance to anti-hypertensive medications

To explore the perceptions and experiences of hypertensive patients toward medication use and adherence.
$\mathrm{N}=440$ and

8 focus groups.

Consecutive

sampling

method was

used to recruit

participants

from a list of

hypertensive

patients of a

poor urban

community. A

purposive

sampling

technique was

used for FGD

from

hypertensive patients.

\section{$\mathrm{N}=130$ \\ Systematic \\ random}

technique was

used to select

hypertensive

patients from a

teaching hospital

$\mathrm{N}=113$

Purposive

sampling was

conducted

among all the

eligible

hypertensive

patients of

inpatients

department of a

specialized

Hospital

Pakistan
$\mathrm{N}=16$

Purposive sampling among hypertensive patients of a government hospital
45.6 Cross-sectional

30.7

Survey and

65.2 qualitative

interviews

Factors associated with adherence: regular clinic

attendance $(\mathrm{p}<0.0001)$; not using non-western prescription medication $(\mathrm{p}<0.001)$; support from family members ( $p=0.038$ ); friends who were concerned about the respondent's hypertension $(\mathrm{p}<0.0001)$ and helpful in reminding the respondent about taking medication $(\mathrm{p}<0.0001)$. Beliefs about cause of hypertension were not associated with compliance $(\mathrm{p}=-0.090)$. Reasons given for MNA in focus group discussion: feeling better, forget to take medication and cost.

Bivariate analysis revealed thatperception of severity of hypertension complications from poor treatment and threat to life positively correlated with medication adherence $(\mathrm{r}=0.46 ; \mathrm{p}<0.0001)$.

MNA was found to be associated with: male gender $\mathrm{p}=0.008$; less monthly income $\mathrm{p}=0.046$ unemployed persons

$(\mathrm{p}=0.002)$; duration of hypertension $<5$ years ( $\mathrm{p}=0.03)$; mono therapy and di-therapy $(\mathrm{p}=0.02)$ and who paid themselves for their drugs $(\mathrm{p}=0.06)$

The majority of the patients carried specific unrealistic beliefs regarding the long-term use of medication; yet these beliefs were heavily accepted and practiced by the society. Physician's attitude, patient's past experiences, and knowledge related to hypertension were noted as major contributing factors thus resulting in non-adherence to prescribed therapy. 


\section{Continued}

38. Saleem et al. 2011 [81]

39. Hashmi et al. 2007 [57]

40. Al-Ramahi et al. 2015 [38]
To evaluate the association between patient's knowledge of hypertension management and medication adherence
Pakistan

Pakistan investigate the factors associated with adherence in the studied population

$$
\mathrm{N}=385
$$
therapy and to
Eligible

hypertensive patients from two tertiary care hospitals
31.2

Cross-sectional observational

64.7

$$
\begin{array}{cc}
\begin{array}{c}
\text { To measure } \\
\text { adherence to }
\end{array} & \begin{array}{c}
\mathrm{N}=460 \\
\text { Randomly } \\
\text { ntihypertensive }
\end{array} \\
\text { selected }
\end{array}
$$

participants

from eligible

hypertensive

patients of two

tertiary care

hospitals

54.6 Cross-sectional 23/23.8

$$
\mathrm{N}=450
$$

Simple random sample from

adherence to antihypertensive therapy and to investigate the

Palestine effect of a range of demographic and psychosocial variables on medication adherence. patients visiting outpatient clinics of governmental primary healthcare centers in addition to a group of private clinics and pharmacies
56.2 Cross-sectional 54.2/54.2
Study shows an inverse association between knowledge scores of hypertension and adherence level.

Correlation coefficient between total score of knowledge of hypertension and total adherence was $-0.170(\mathrm{p}<0.001)$

Factors significantly improved adherence (univariate analyses) were increasing age, better awareness, increasing number of pills prescribed

(by multivariate analyses): number of drugs that a patient was taking $(\mathrm{p}=0.02)$ and whether he/she was taking medication regularly or only for symptomatic relief $(\mathrm{p}=0.00001)$

Factors significantly associated with MNA: younger age ( $<45$ years) $(\mathrm{AOR}=1)$, living in a village $(\mathrm{AOR}=1)$,

forgetfulness $(\mathrm{AOR}=5.12$; 95\% CI: 3.12 - 8.41) dissatisfaction with treatment $(\mathrm{AOR}=2.93$; 95\% CI: 1.22 - 7.02), side effects $(\mathrm{AOR}=4.58 ; 95 \%$ CI: $1.87-11.25)$, fear of getting used to medication

$$
(\mathrm{AOR}=8.00 \text {; }
$$
95\% CI: 2.44 - 26.19) and evaluating health status as very good, good or poor $(\mathrm{AOR}=1)$. Other factors (by univariate analysis): having lower income ( $\mathrm{p}=0.035)$; receiving a higher number of antihypertensive tablets ( $\mathrm{p}=0.001)$; a higher dosing frequency ( $p \leq 0.0001)$ and having no other chronic disease $(p=0.009)$. 


\section{Continued}

41. Zyoud et al. 2013 [82]

42. Lalic et al.

43. Edo, TA. 2009 [83]

44. Bovet et al. 2002 [84]
To investigate

factors associated with adherence to

therapy among hypertensive

patients and assess the relationship

between

medication

adherence and

treatment

satisfaction

To evaluate the

degree of

adherence in

hypertensive

patients and to

study risk factors

affecting

adherence

and the effects of

non-adherence on

BP

Seychelles

Seychelles

\section{$\mathrm{N}=410$}

Convenient sampling of

hypertensive

patients from

outpatients of a clinic and a

hospital

$52 \%$

36.8

$$
\mathrm{N}=170
$$

All eligible

hypertensive

patients treated

in a primary

health care

outpatients
65.9 Cross-sectional

25.88

56.86 descriptive-co relational study
$\mathrm{N}=102$

Systematic

random

sampling from

all eligible

hypertensive patients

registered at two

public health

centres

people

To examine the

compliance to

medication among

newly diagnosed

hypertensive

patients screened

from the general

population of the

Seychelles
After adjusting the

covariates using

multiple regression,

global treatment

satisfaction was

statistically significantly

$(\mathrm{p}=0.001)$ associated

with medication

adherence

( $\mathrm{R}=0.373$; adjusted

$\mathrm{R} 2=0.122 ; \mathrm{F}=8.107 ; \mathrm{d}$

$\mathrm{f}=8 ; \mathrm{p}<0.001)$

MNA was associated with elderly patients, longer duration of

therapy and side effects

of drugs. $(\mathrm{p}<0.01)$.

Patients $<65$ years

were found to be

more likely to

adhere to their

medication regimen,

compared to elderly patients

$\left(\chi^{2}=21.3 ; \mathrm{p}<0.01 ;\right.$

$\mathrm{OR}=6.0 ; 95 \% \mathrm{CI}$ :

2.76 - 13.04). BP values over $140 / 90 \mathrm{mmHg}$

were reported in

$59.1 \%$ of MNA

patients and in

$21.4 \%$ of adherent

patients $\left(\chi^{2}=19.84\right.$;

$\mathrm{p}<0.01 ; \mathrm{OR}=5.30 ; 95 \%$

CI: 2.39 - 11.85)

Significant determinants of compliance

behaviour: individual perception of the

benefits of hypertension treatment $(\mathrm{p}=0.0004)$; individual perception of risks of hypertension treatment $(\mathrm{p}=0.0120)$ and cues to action $(\mathrm{p}=0.0025)$

12-month adherence was higher with: skilled workers ( $\mathrm{p}=0.034)$; who knew their BP before diagnosis $(\mathrm{p}=0.028)$ and who thought current lifestyle was important for future health $(\mathrm{p}=0.050)$ 


\section{Continued}

\begin{tabular}{|c|c|c|c|c|c|c|c|}
\hline $\begin{array}{l}\text { 45. Elzubier et al. } \\
2000 \text { [52] }\end{array}$ & Sudan & $\begin{array}{c}\text { To estimate } \\
\text { adherence with } \\
\text { drug use, } \\
\text { associated factors, } \\
\text { and the effect of } \\
\text { adherence on BP } \\
\text { control }\end{array}$ & $\begin{array}{c}\mathrm{N}=198 \\
\text { Registered } \\
\text { eligible } \\
\text { hypertensive } \\
\text { patient attended } \\
\text { medicine } \\
\text { department of a } \\
\text { teaching hospital }\end{array}$ & 76.3 & Cross sectional & 40.4 & $\begin{array}{l}\text { Using multiple logistic } \\
\text { regression analysis only } \\
\text { variable that is positively } \\
\text { and significantly associated } \\
\text { with MNA is being unable } \\
\text { to buy drugs }(\mathrm{p}<0.001)\end{array}$ \\
\hline $\begin{array}{l}\text { 46. Joho et al. } \\
2012[32]\end{array}$ & Tanzania & $\begin{array}{l}\text { To investigate } \\
\text { factors affecting } \\
\text { treatment } \\
\text { adherence with } \\
\text { antihypertensive } \\
\text { therapy among } \\
\text { hypertensive } \\
\text { patients with the } \\
\text { guide of the HBM } \\
\text { conceptual } \\
\text { framework }\end{array}$ & $\begin{array}{c}\mathrm{N}=135 \\
\text { Randomly } \\
\text { selected patient } \\
\text { from three } \\
\text { hypertensive } \\
\text { clinics }\end{array}$ & 56.3 & Cross sectional & $44 / 35.44$ & $\begin{array}{l}\text { With the use of bivariate } \\
\text { analysis treatment } \\
\text { compliance showed } \\
\text { significant positive } \\
\text { association with perceived } \\
\text { benefit }(\mathrm{r}=0.27 ; \mathrm{p}=0.001) \\
\text { cues to action }(\mathrm{r}=0.19 ; \\
\mathrm{p}=0.022) \text {. Treatment } \\
\text { adhrence showed } \\
\text { significant negative } \\
\text { association with: } \\
\text { perceived barrier to } \\
\text { treatment }(\mathrm{r}=-0.53 ; \\
\mathrm{p}=0.000)\end{array}$ \\
\hline $\begin{array}{l}\text { 47. Mukora-Mutseyekwa } \\
\text { et al. } 2013 \text { [85] }\end{array}$ & Zimbabwe & $\begin{array}{l}\text { Measurement of } \\
\text { BP control } \\
\text { achievement, } \\
\text { estimating } \\
\text { prevalence of drug } \\
\text { adherence } \\
\text { behaviour and } \\
\text { establishing the } \\
\text { association } \\
\text { between drug } \\
\text { adherence } \\
\text { behaviour and } \\
\text { achievement } \\
\text { of BP control }\end{array}$ & $\begin{array}{c}\mathrm{N}=102 \\
\text { Convenience } \\
\text { sampling from } \\
\text { outpatients of a } \\
\text { tertiary hospital }\end{array}$ & 69.6 & Cross-sectional & $59.8 / 66.19$ & $\begin{array}{l}\text { Participants with normal } \\
\text { BP measurements were } \\
\text { more than three times as } \\
\text { likely to report maximal } \\
\text { adherence to prescribed } \\
\text { drug schedule } \\
\text { (AOR }=3.37: \\
\text { 95\% CI: } 1.38-8.24)\end{array}$ \\
\hline
\end{tabular}

Note: $\mathrm{MNA}=$ medication non-adherence; $\mathrm{BP}=$ Blood pressure; $\mathrm{OR}=$ odds ratio; $\mathrm{AOR}=$ adjusted odd ratio; $r=$ Pearson's correlation coefficient. ${ }^{\mathrm{a}} \mathrm{Patient}$ population comprised of both male and female. 
Submit or recommend next manuscript to SCIRP and we will provide best service for you:

Accepting pre-submission inquiries through Email, Facebook, LinkedIn, Twitter, etc. A wide selection of journals (inclusive of 9 subjects, more than 200 journals)

Providing 24-hour high-quality service

User-friendly online submission system

Fair and swift peer-review system

Efficient typesetting and proofreading procedure

Display of the result of downloads and visits, as well as the number of cited articles Maximum dissemination of your research work

Submit your manuscript at: http://papersubmission.scirp.org/

Or contact ojepi@scirp.org 